\title{
Pharmacokinetics of monoclonal antibodies and Fc-fusion proteins
}

\author{
Liming Liu ${ }^{\bowtie}$ \\ Department of Pharmacokinetics, Pharmacodynamics and Drug Metabolism, MRL, West Point, PA 19486, USA \\ $\square$ Correspondence: liming_liu2@merck.com (L. Liu) \\ Received February 20, 2017 Accepted March 23, 2017
}

\begin{abstract}
There are many factors that can influence the pharmacokinetics (PK) of a mAb or Fc-fusion molecule with the primary determinant being FcRn-mediated recycling. Through Fab or Fc engineering, IgG-FcRn interaction can be used to generate a variety of therapeutic antibodies with significantly enhanced half-life or ability to remove unwanted antigen from circulation. Glycosylation of a mAb or Fc-fusion protein can have a significant impact on the PK of these molecules. mAb charge can be important and variants with $\mathrm{pl}$ values of 1-2 unit difference are likely to impact PK with lower pl values being favorable for a longer half-life. Most mAbs display target mediated drug disposition (TMDD), which can have significant consequences on the study designs of preclinical and clinical studies. The PK of mAb can also be influenced by anti-drug antibody (ADA) response and off-target binding, which require careful consideration during the discovery stage. mAbs are primarily absorbed through the lymphatics via convection and can be conveniently administered by the subcutaneous (sc) route in large doses/volumes with co-formulation of hyaluronidase. The human PK of a mAb can be reasonably estimated using cynomolgus monkey data and allometric scaling methods.
\end{abstract}

KEYWORDS monoclonal antibody (mAb), Fc-fusion protein, pharmacokinetics, FcRn, target-mediated drug disposition (TMDD), glycosylation, anti-drug antibody (ADA), human PK prediction

\section{INTRODUCTION}

The ground-breaking discovery of monoclonal antibody (mAb) technology by Kohler and Milstein in 1975 provided the possibility of creating antibodies as a class of therapeutics (Kohler \& Milstein, 1975). The original obstacles of immunogenicity of murine mAbs in humans was overcome by the revolution in molecular biology in the 1980s, which enabled humanization of murine antibodies and, eventually, the successful development of fully humanized antibodies. Humanization greatly reduces a therapeutic antibody's immunogenicity in humans, making chronic administration possible. Such advances in antibody technologies have resulted in an explosion in the development of therapeutic mAbs over the last decade. Today, more than $47 \mathrm{mAbs}$ and derivative drugs have been approved for human use with many of them attaining blockbuster status (Ecker et al., 2015). Among the top ten selling drugs in 2014, five were monoclonal antibodies and one was an Fc fusion molecule, with each having an annual revenue over 6.5 billion US dollars (Nisen, 2015). It is estimated that in the near future, about $30 \%$ of the new drugs will be antibodies or antibody derivatives (Elvin et al., 2013). Antibody derivatives include Fc-fusion proteins, antibody-drug conjugates (ADCs), immunocytokines (antibody-cytokine fusions), and antibody-enzyme fusions.

The efficacy of a mAb is largely dependent on its pharmacological and pharmacokinetic properties. The pharmacological effects or pharmacodynamics (PD) of a mAb are best described as "What a drug does to the body"; a mAb binds to a target (e.g., receptors, soluble antigens, etc.) and induces either antagonistic (i.e., blocking or neutralizing) or agonistic effects (i.e., activating), triggering down-stream pharmacological effects, leading to efficacy and/or unwanted side effects. The pharmacokinetics (PK) of a mAb is best described by "What the body does to the drug". The fate of a mAb in vivo will be determined by how the body handles it under physiological or pathological conditions. The clearance or half-life of a mAb will determine the body's "exposure" to the mAb, which in turn will determine the extent of PD effects. The exposure-response (PK-PD) relationship determines the outcome of a drug's effects on the body. 
Understanding this relationship is an essential and integral part of drug discovery and development.

Being large proteins of $150 \mathrm{kDa}$, mAbs possess some unique PK properties, making the discovery and development pathway of mAbs substantially different from that of small molecule drugs. The unique PK properties are determined by many factors related to an antibody's structure and functions including FcRn mediated recycling, glycosylation patterns, overall charge and pl, target-mediated clearance, anti-drug antibody response, and off-target binding.

In this review article, general PK properties and the factors influencing the PK of $\mathrm{mAbs}$ and $\mathrm{Fc}$ fusion proteins will be discussed, in addition to $\mathrm{PK}$ topics related to preclinical and early clinical development of mAb drugs. The impacts of glycosylation on the PK and PD of mAbs and Fc-fusion proteins have been reviewed extensively elsewhere (Liu, 2015) and will be only briefly discussed here.

\section{FACTORS INFLUENCING THE PK OF MAB AND FC-FUSION PROTEINS}

An antibody is a complex molecule consisting of an antigen binding region (Fab domain) and a constant region (Fc domain). Fab binds to antigens and can be responsible for target-mediated clearance of a mAb. Glycosylation and charges in the Fab domain are also important for the PK properties of a mAb. In the Fc region, a subdomain of the $\mathrm{C}_{\mathrm{H} 2}-\mathrm{C}_{\mathrm{H} 3}$ domain is responsible for $\mathrm{FcRn}$ binding that results in recycling of antibodies for a long half-life (Roopenian \& Akilesh, 2007). The same $\mathrm{C}_{\mathrm{H} 2}-\mathrm{C}_{\mathrm{H} 3}$ domain is also responsible for Protein $A$ and $G$ binding, which is exploited for antibody purification (Kim et al., 1994b). The $\mathrm{C}_{\mathrm{H} 1}-\mathrm{C}_{\mathrm{H} 2}$ domain is responsible for FcyR binding, which is critical for antibody effector functions (Daëron, 2014; Jefferis \& Lund, 2002). A canonical glycosylation site is located in the $F C$ region $\mathrm{C}_{\mathrm{H} 2}$ domain (Asn297) in all IgG subclasses. Glycosylation patterns can impact both PK and PD significantly (Arnold et al., 2007; Jefferis, 2009a). The PK properties related to the structure of $\mathrm{Fc}$ are also relevant to Fc-fusion
Figure 2. FcRn mediated IgG recycling pathway and antibody mediated antigen removal via $\mathrm{pH}$ dependent binding. (A) lgG circulating in the blood is taken up by endothelial cells or monocytes through either fluid phase pinocytosis or receptor mediated endocytosis. Once inside the cells, IgG binds to FcRn in the acidified endosomes. IgG that binds to FcRn migrates to the cell surface where the IgG encounters a physiological $\mathrm{pH}$ environment $(\sim \mathrm{pH}$ 7.4) and is released back into the blood. $\lg$ that is not bound to FcRn (due to competition with other IgG) will be sorted to lysosomes for degradation. (B) mAb (with strong binding at $\mathrm{pH} 7.4$ and no or weak binding at $\mathrm{pH} 6$ ) binds to antigen at neutral $\mathrm{pH}$ in the circulation; once endocytosed into the cell and entered the acidic endosome, the antibody releases the antigen and binds to FcRn. FcRn bound antibody recycles back to the blood stream while the antigen is degraded in the lysosome.

molecules. In addition, the fusion partner replaces Fab and may be responsible for target mediated clearance. Figure 1 depicts the general structure of $\lg \mathrm{G} 1$ and the specific domains that are important for PK properties.

\section{FcRn: key regulator of IgG PK}

In the 1960s, Dr. Roger Brambell proposed a mechanism by which IgG is salvaged from catabolism by receptors located within cellular compartments and/or on the surface of cells (Brambell et al., 1964; Brambell, 1966). The "hypothesized" Brambell receptor, later called neonatal Fc receptor (FcRn), was cloned in 1989 (Simister \& Mostov, 1989). Experiments in FcRn knockout mice have definitively confirmed that FcRn is responsible for protecting IgG from catabolism (Junghans, 1997; Roopenian \& Akilesh, 2007). Over the past two decades, extensive work by many investigators has established the role of FcRn in regulating the levels and transport of $\lg G$ in the body (Roopenian \& Akilesh, 2007), validating Brambell's hypothesis. It is now established that FcRn binds to IgG at acidic $\mathrm{pH}(\sim 6.0)$ with very low or negligible affinity at pH 7-7.4 (Ghetie \& Ward, 1997; Roopenian \& Akilesh,

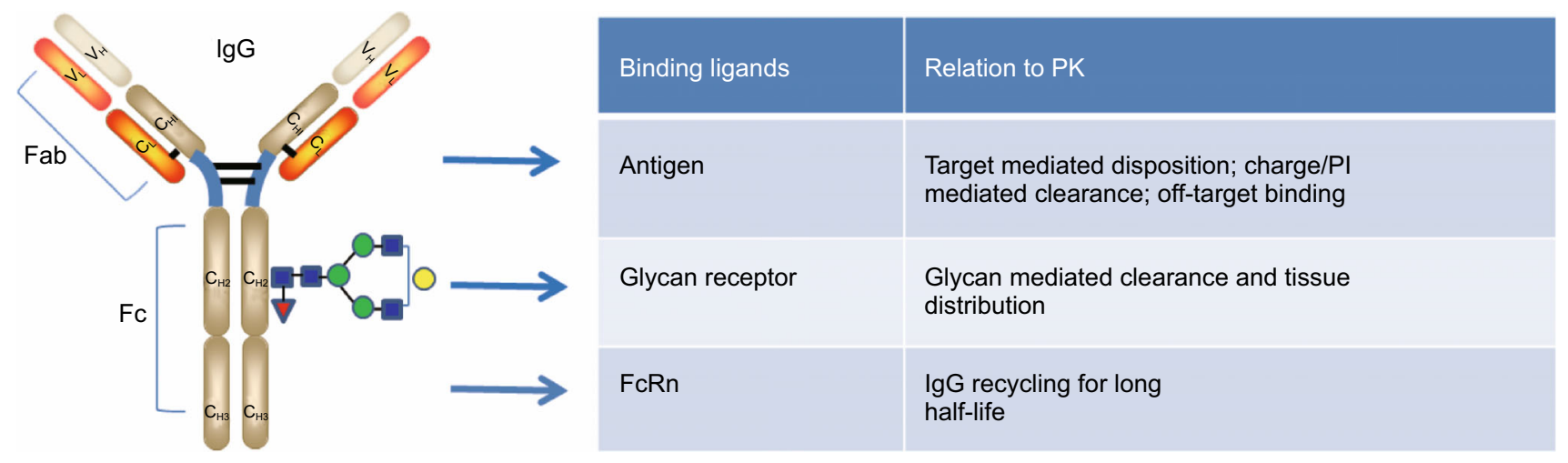

Figure 1. Antibody features that contribute to PK properties. 
A

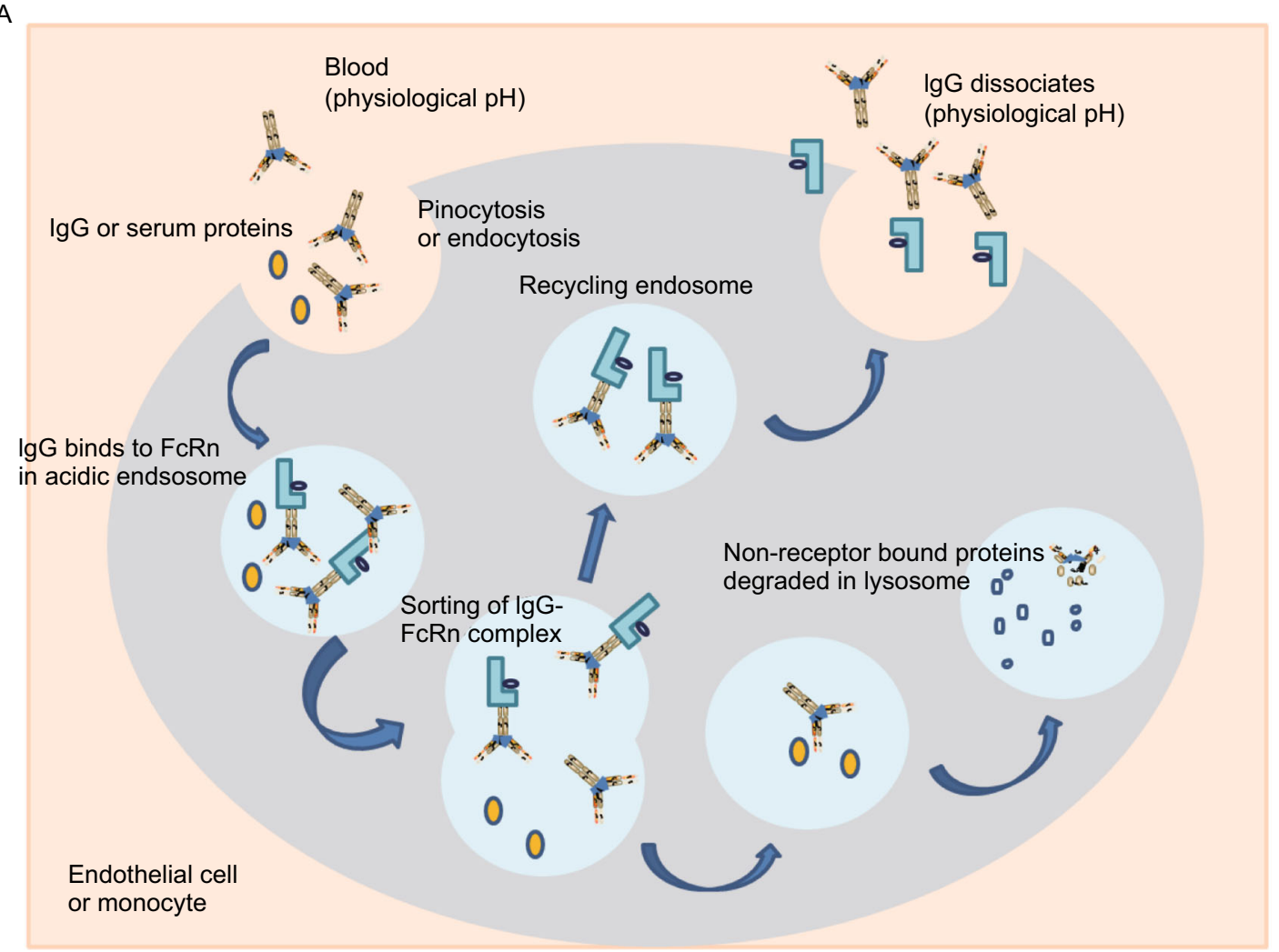

B
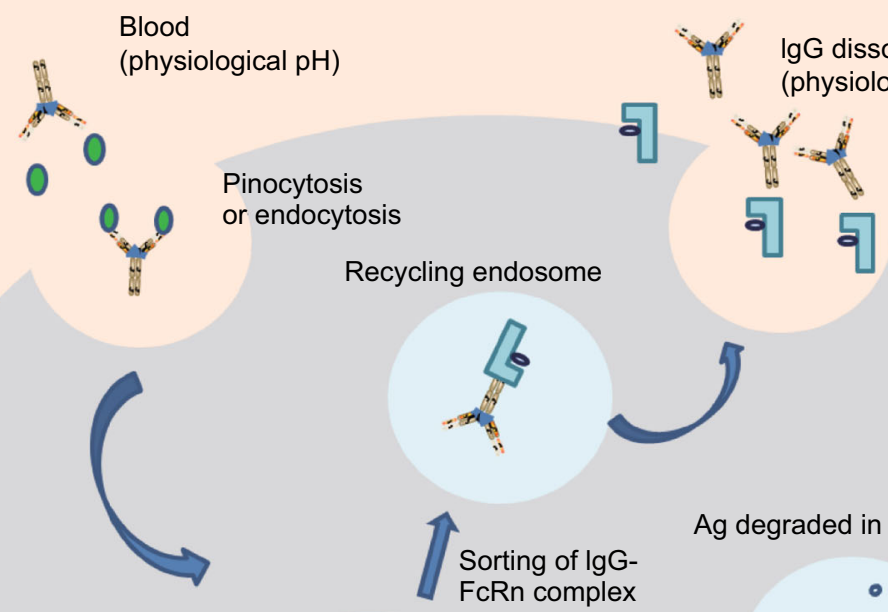

Ag degraded in lysosome

$\lg \mathrm{G}$ binds to $\mathrm{FcRn}$

Ag dissociated from $\mathrm{Ab}$

in acidic endososome

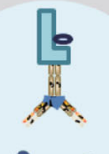

FcRn complex

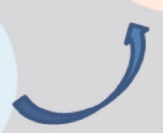

0

Endothelial cell or monocyte 
2007), providing an ingenious biological solution to achieve exocytic release of recycled IgG. The binding area of IgG to FcRn is located between the $\mathrm{C}_{\mathrm{H} 2}$ and $\mathrm{C}_{\mathrm{H} 3}$ domain, distinctly different from the FcyR binding domain that is located between the $\mathrm{C}_{\mathrm{H} 1}$ and $\mathrm{C}_{\mathrm{H} 2}$ domain (Kim et al., 1994a; Roopenian \& Akilesh, 2007). As depicted in Figure 2A, IgG circulating in the blood is taken up by endothelial cells or monocytes through either fluid phase pinocytosis or receptor-mediated endocytosis. Once inside the cells, IgG binds to FcRn in the acidic endosomes. IgG that binds to FcRn escapes lysosomal degradation and migrates to the cell surface where the IgG encounters a physiological ( $\sim \mathrm{pH} 7.4)$ $\mathrm{pH}$ environment and is released back into the blood. IgG that is not bound to FcRn (due to competition of other $\mathrm{lgG}$ ) will be sorted to lysosomes for degradation (Fig. 2A). Through competition of FcRn binding for recycling, the body can regulate IgG homeostasis: more IgG will be sorted to lysosomes for degradation when large amounts of IgG are present whereas more IgG will be rescued through recycling when the $\lg G$ concentration is low (Roopenian \& Akilesh, 2007).

The elucidation of FcRn biology prompted active efforts by the biopharmaceutical industry to create therapeutic mAbs with super long half-lives through Fc engineering. The amino acids in the Fc region have been thoroughly investigated to identify mutations that significantly enhance binding to $\mathrm{FcRn}$ at $\mathrm{pH} 6$ while maintaining little or no binding at neutral $\mathrm{pH}$ (7.4). It has been reported that specific $\mathrm{Fc}$ variants (T250Q/M428L, V308P, M428L, M252Y/S254T/T256E, M428L/N434S, N434A, N434H) that improve IgG affinity for $\mathrm{FcRn}$ at $\mathrm{pH} 6$ with little or no binding to FcRn at neutral $\mathrm{pH}$ can lead to 2-4-fold longer terminal half-lives in cynomolgus and rhesus monkeys (Yeung et al., 2009, 2010; Vaccaro et al., 2005; Olafsen, 2012; Hinton et al., 2004,2006; Deng et al., 2010; Datta-Mannan et al., 2007a, b, 2012a, b). This general relationship has also been validated more recently in humans with the M252Y/S254T/T256E (YTE) set of mutations constructed on the $\mathrm{Fc}$ of a mAb against respiratory syncytial virus (RSV) with half-life increases from around 20 days to more than 60 days (Robbie et al., 2013). However, a good quantitative relationship between in vitro FcRn binding affinity and in vivo half-life has not been wellestablished (Datta-Mannan \& Wroblewski, 2014), suggesting that factors other than FcRn interaction also play an important role. On the opposite end, reduction of IgG half-life can be realized for in vivo diagnostic and research purposes by engineering poor binders of FcRn (Swiercz et al., 2014; Olafsen et al., 2006). In addition, blockade of FcRn in vivo can decrease endogenous IgG half-life to treat autoimmune diseases (Patel et al., 2011; Liu et al., 2007; Challa et al., 2013).

FcRn binding affinity is one of the critical quality attributes (CQA) for therapeutic mAb manufacturing processes (Alt et al., 2016). Methionine in mAbs can be oxidized during manufacturing processes (Tsuchida et al., 2016). The Fc region of human $\operatorname{lgG} 1$ has three conserved methionine residues (Met252, Met358, and Met428), which are located near the $\mathrm{C}_{\mathrm{H} 2}-\mathrm{C}_{\mathrm{H} 3}$ interface where $\mathrm{FcRn}$ binds (Alt et al., 2016). It has been shown that the oxidation of these three Met residues impairs Fc-FcRn binding (Bertolotti-Ciarlet et al., 2009; Pan et al., 2009). When $79 \%$ of Met252 and $57 \%$ of Met428 were oxidized, the serum half-life of $\lg$ decreased by about $83 \%$ in mice (Wang et al., 2011b). More recently, Gao et al. showed with mutagenesis analyses that either M252 or M428 oxidation alone significantly impaired Fc-FcRn binding. M252 oxidation generated a more deleterious effect on Fc-FcRn binding than M428 oxidation, whereas M358 oxidation did not affect Fc-FcRn binding (Gao et al., 2015).

Although it is the $\mathrm{C}_{\mathrm{H} 2}-\mathrm{C}_{\mathrm{H} 3}$ domain of $\mathrm{FC}$ that is primarily involved in the binding to $\mathrm{FcRn}$, the variable region $(\mathrm{Fv})$ of Fab may also interact with FcRn and alter the interaction between IgG molecules and FcRn. Wang et al. found that although mAbs with identical Fc and different Fab exhibited a differential binding to FcRn at both $\mathrm{pH} 6$ and $\mathrm{pH} 7.3$, only the dissociation characteristics at $\mathrm{pH} 7.3$ correlated with the in vivo $\mathrm{PK}$ properties of these mAbs (the slower the dissociation at $\mathrm{pH} \mathrm{7.3,} \mathrm{the} \mathrm{shorter} \mathrm{the} \mathrm{half-life)} \mathrm{(Wang} \mathrm{et} \mathrm{al.,}$ 2011a). More recently, Schoch et al. made similar observations with ustekinumab and briakinumab, both anti-IL12/IL23 mAbs, which have almost identical Fc but different Fab fragments (Schoch et al., 2015). The binding affinity to FcRn at $\mathrm{pH} 6$ and the $\mathrm{PI}$ are very similar between these two mAbs, but there is a positive charge patch in the Fv of briakinumab, which renders strong binding to FcRn. The mAb therefore only dissociates from $\mathrm{FcRn}$ at higher $\mathrm{pH}$, resulting in a shorter half-life for briakinumab ( $t_{1 / 2} \sim 9$ days), in comparison to ustekinumab ( $t_{1 / 2} \sim 22$ days) (Schoch et al., 2015). These results clearly indicate that the variable region does also influence lgG-FcRn interactions, thus impacting $\mathrm{PK}$ of a mAb.

Antibody and antigen complexes are also recycled through the FcRn pathway and can result in accumulation of bound antigens in the circulation and extension of the halflife of the antigens (Igawa et al., 2013). To effectively remove antigen from the circulation, it is desired that the bound antigens be degraded, while antibody is recycled. Through antibody engineering to render Fab binding to antigens $\mathrm{pH}$ dependent (strong binding at $\mathrm{pH} 7.4$ and no or weak binding at $\mathrm{pH} 6$ ), Igawa et al. created an elegantly designed recycling antibody that directs antigens for lysosomal degradation while ensuring that the $\mathrm{mAb}$ is recycled to bind antigen again, thus reducing antigen concentrations (Fig. 2B) (Igawa et al., 2010a, 2013). Furthermore, they created a sweeping antibody through engineering $\mathrm{pH}$-dependent antigen binding in the $\mathrm{Fv}$ region and higher binding affinity to FcRn or FcyRIIB in the Fc region. The sweeping antibody can bind to FcRn or FcyRIlb at neutral $\mathrm{pH}$ to facilitate the uptake of the immune complex; bound antigen (such as IL-6R) dissociates from the antibody for degradation once in the lysosome, resulting in a significantly reduced antigen concentration (Igawa et al., 2016). However, the sweeping antibodies are 
also cleared significantly faster than conventional antibodies, likely due to these antibodies' ability to bind FcRn at neutral $\mathrm{pH}$, which prevents them from being recycled back to the circulation (Igawa et al., 2016). It appears that the sweeping antibody targeting FcyRIlb for enhanced uptake does not have this drawback (Igawa et al., 2016).

Other factors related to FcRn functions that can impact the $\mathrm{PK}$ of a mAb include FcRn polymorphism and IgG allotypes. It has been shown that the polymorphism of the variable number of tandem repeats region in the FcRn promoter can influence the FcRn expression level and binding ability (Sachs et al., 2006). IgG allotype can also influence the binding affinity of a mAb to FcRn, with better binders having longer half-life, which may contribute to the variability of PK in the clinic (Ternant et al., 2016). For example, it has been shown that a mAb with the G1m17,1 allotype, such as infliximab, has better binding affinity for FcRn than those with the $\mathrm{G} 1 \mathrm{~m} 3$ with no $\mathrm{G} 1 \mathrm{~m} 1(\mathrm{G} 1 \mathrm{~m} 3,-1)$ allotype. In patients homozygous for the $\mathrm{G} 1 \mathrm{~m} 17,1$ allotype, infliximab is in competition with endogenous IgG with the G1m17,1 allotype. As a result, infliximab exhibits a shorter half-life in patients homozygous for the G1m17,1 allotypes than in those carrying the G1m3,-1 allotype (Ternant et al., 2016). In addition, baseline albumin level in the serum can be used to predict the functional status of FcRn in vivo in that the trough level of an administered mAb correlate positively with the baseline albumin concentration (Fasanmade et al., 2010).

Although FcyR binding is critical for IgG's effector functions such as antibody dependent cell-mediated cytotoxicity (ADCC) and complement dependent cytotoxicity (CDC), FcyR does not appear to significantly affect IgG's PK properties. This is likely due to the fact that a large pool of serum IgG can compete with the binding of relatively small amounts of $m A b$ to FcyR, effectively ameliorating the impact of FcyR binding. Consistent with this, Abuqayyas and coworkers have shown that $8 \mathrm{C} 2$, a mouse $\lg \mathrm{mAb}$, exhibited similar $\mathrm{PK}$ and tissue distribution in both FcyR knockout mice and in wild type mice (Abuqayyas et al., 2013).

\section{Glycosylation impacts on PK of mAb and Fc-fusion proteins}

Like natural IgGs, all approved recombinant therapeutic mAbs are glycosylated, although some non-glycosylated mAbs or derivatives are in clinical development (Liu, 2015). Therapeutic mAbs or derivatives have an asparagine (Asn)$X-S e r / T h r$ (Where $X$ is any amino acid except Pro) consensus sequence for $N$-glycosylation at the position Asn297 in the heavy chain of the $\mathrm{C}_{\mathrm{H} 2}$ constant domain. Some therapeutic mAbs also bear additional glycosylation in the Fab domain. For instance, cetuximab is glycosylated at Asn88 of the $\mathrm{VH}$ region (Jefferis, 2009b). In addition, some of the Fcfusion partner molecules, such as etanercept and B cell activating factor receptor 3 (BR3)-Fc, also possess O-linked glycans (Pennica et al., 1993; Stefanich et al., 2008).
Characterization of aglycosylated IgG, produced through chemical modification or genetic engineering, confirmed that glycosylation is not required for an IgG antibody's long halflife (Kim et al., 1994a; Liu et al., 2011; Nose \& Wigzell, 1983; Tao \& Morrison, 1989). The clinical evidence for aglycosylated IgG having normal $P K$ is demonstrated by the $m A b$ ALD518, a humanized anti-human IL-6 lgG1 produced in yeast. In a phase I clinical trial, the circulating half-life for ALD518 was 20-32 days, consistent with half-life of a normal human IgG1 (Clarke et al., 2009). Glycosylated mAbs with terminal high mannose glycans have been shown to exhibit fast clearance from the blood (Goetze et al., 2011; Kanda et al., 2007; Liu et al., 2011; Wright \& Morrison, 1994; Wright et al., 2000; Yu et al., 2012). The fast clearance of mAbs containing high mannose has also been demonstrated in clinical studies (Chen et al., 2009; Goetze et al., 2011). Glycan receptors that have been attributed to the removal of glycoproteins in vivo include the mannose receptor (ManR) and the asialoglycoprotein receptor (ASGPR). The ASGPR and the ManR are carbohydrate-specific, endocytic receptors expressed by hepatic parenchymal (hepatocytes) and nonparenchymal (such as Kupffer) cells, and sinusoidal endothelial cells, respectively (Ashwell \& Harford, 1982; Mi et al., 2014).

The shorter half-life of an Fc-fusion molecule in comparison to the whole $\lg G$ has been attributed to the lower binding affinity to FcRn, the glycan mediated disposition and the receptor (of fusion partner) mediated disposition (Liu, 2015). Among these attributes, glycosylation patterns may play a more important role in determining the in vivo clearance of Fc-fusion molecules. For example, in the investigation of humanized yeast-produced TNFaRII-Fc-fusion molecules, it was demonstrated that it was the extent of sialylation on the TNFRII, not the FcRn-binding affinity, which determined the clearance. The exposure was positively correlated to the quantity of the sialylation on the receptor molecule, with higher sialic acid content resulting in higher exposure (Liu et al., 2013).

Most of the Fc-fusion molecules including BR3-Fc, IL-23R-FC, CTLA4-Ig, and LFA3TIP rely on sialylation in reducing the in vivo clearance (Liu, 2015). Other terminal monosaccharide, such as GlcNAc, can also contribute to the PK properties of Fc-fusion molecules (Keck et al., 2008; Jones et al., 2007).

\section{Impact of charge and pl on mAb PK}

Isoelectric point ( $\mathrm{pl})$, a measurement of protein charge, is defined as the $\mathrm{pH}$ at which the protein carries no net electrical charge. In general, antibodies that are chemically or genetically modified to achieve higher, more basic, pl values exhibit a high propensity to adhere to anionic sites of cell surfaces, resulting in increased tissue uptake and fast clearance from circulation. In contrast, modified antibodies with lower, more acidic $\mathrm{pl}$ values have a lower rate of uptake 
into cells (as a result of repulsion from the negatively charged cell surface), leading to decreased tissue uptake and blood clearance (Boswell et al., 2010; Bumbaca et al., 2012, 2015; Igawa et al., 2010c; Kobayashi et al., 1999; Lee \& Pardridge, 2003). Chemically modified Fabs with a pl reduction of 1-2 units showed decreased blood clearance and tissue accumulation relative to the unmodified Fab (Kobayashi et al., 1999). With antibody pl variants generated using site-directed mutagenesis in the Fab region, Igawa et al. demonstrated that variants with pl values of 1-2 units lower than the wild type displayed longer half-lives and reduced clearance following both subcutaneous and intravenous administration (Igawa et al., 2010b). The data demonstrated that the clearance was positively correlated with $\mathrm{pl}$, i.e., the half-life was negatively correlated with pl. Similar data was obtained from both human and minipig model in that antibodies with higher pl values exhibited faster clearance and lower subcutaneous bioavailabilities than antibodies with lower pl values (Zheng et al., 2012). Manipulation of $\mathrm{pl}$ was also used to reduce the toxicity of immunotoxin. Onda et al. showed that reducing the $\mathrm{pl}$ of the $\mathrm{Fv}$ portion of an immunotoxin significantly reduced liver toxicity, presumably reducing the distribution to the liver (Onda et al., 1999).

Charge variations can arise from antibody manufacturing processes due to chemical or enzymatic degradation via oxidation, deamidation, isomerization, and fragmentation. The charge differences may impact both PK and PD. To investigate whether $\mathrm{mAb}$ charge variants possess different PK and PD properties, Khawli et al. isolated basic, neutral, and acidic variants from a mAb product and characterized them in PK and PD assays. Their results showed that all variants had similar potency in PD assays and rat FcRn binding relative to the starting material. Following iv or Sc administration in rats, no difference in serum PK was observed, indicating that $\mathrm{pl}$ differences among charge variants were not sufficient to result in PK changes. However, it is worth noting that the $\mathrm{pl}$ difference between the acidic variant and the basic variants were less than 0.5 (8.7 vs. 9.1) (Khawli et al., 2010). Based on the above evidence, it can be concluded that shifts in isoelectric point of approximately one $\mathrm{pl}$ unit or more are likely to produce measurable changes in PK and tissue distribution; differences of less than one pl unit are mostly inconsequential to PK.

Changing the pl of a mAb is a potentially powerful way to improve PK properties of some mAbs, especially those having strong target-mediated clearance, such as antibodies targeting surface receptors. For example, Igawa et al. modified the variable region to reduce the $\mathrm{pl}$ of an anti-IL6R $\mathrm{mAb}$, resulting in a 2.4-fold half-life extension and 4.4-fold reduction in clearance (Igawa et al., 2010b). With mAb pl ranging from 7.2 to 9.2 , they demonstrated a strong relationship between pl and PK (half-life and clearance) (Fig. 3). Sampei et al. identified a positive charge patch on an antiFIXa antibody that was implicated in causing fast clearance. They introduced a negatively charged amino acid (Tyr30glu)
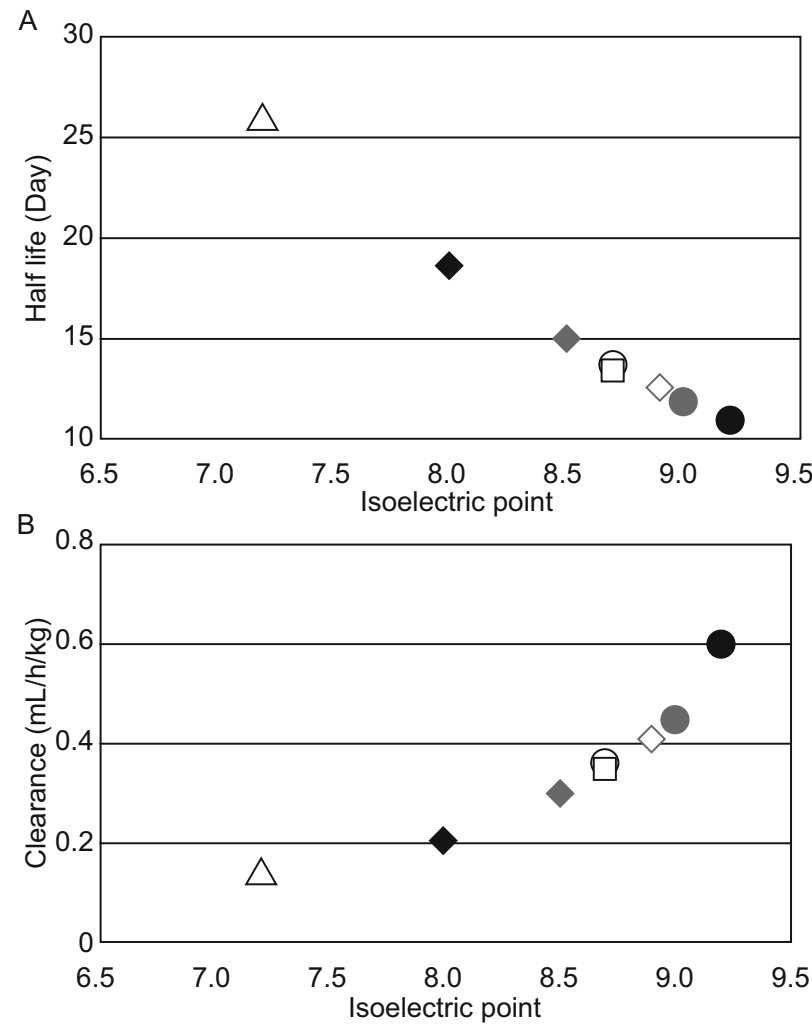

Figure 3. Relationship between charge/pl and half-life and clearance in PK of mAbs. Reproduced from Igawa et al., with permission (2010b).

near the patch and observed a significant improvement in PK (Sampei et al., 2013). More recently, Li et al. showed that an humanized anti-HCV mAb with human $\mathrm{kl}$ and $\mathrm{VH} 3$ framework exhibited unexpectedly fast clearance that was related to a higher framework pl rather than FcRn binding or target-mediated disposition (Li et al., 2014). A humanized $\mathrm{mAb}$ with framework modification resulting in lower pl had significantly improved PK profile (Li et al., 2014). They also confirmed that high $\mathrm{pl} \mathrm{mAb}$ exhibited higher distribution to liver and spleen than did low pl mAb.

It is worth noting that the above observations on the impact of pl on PK were based on work with mAbs against the same targets. mAbs that bind to different targets may not be directly comparable based on pl alone; individual mAbs against different targets have their own physicochemical characteristics that may uniquely contribute to PK properties. For instance, Bevacizumab, a humanized mAb against VEGF, with a pl of 8.2 due to $\mathrm{kI} / \mathrm{VH} 3$ scaffold, exhibited normal $\mathrm{PK}$ in rats whereas the aforementioned anti-HCV $\mathrm{mAb}$, with pl of 8.2 with the same framework, exhibited poor PK (Li et al., 2014). In addition, for a panel of 13 antibodies humanized on a kl, VH3 scaffold, clearance in rats is not correlated with pl (Li et al., 2014). Furthermore, Hotzel et al., testing a larger panels of mAbs in cynomolgus monkeys, found that PK was not correlated with $\mathrm{pl}$ although the $\mathrm{pl}$ of 
the mAbs tested was narrowly clustered, between 7.5 and 9.5 (Hotzel et al., 2012a).

\section{Impact of target-mediated drug disposition on mAb PK}

Target-mediated drug disposition (TMDD) is a nonlinear PK phenomenon, where drug-target binding (complexation with receptors, enzymes, or transporters) and subsequent events (dissociation and drug-target complex degradation) result in dose-dependent changes in PK (Mager \& Jusko, 2001). In comparison to small molecule drugs, TMDD is more common for mAb drugs, especially for those targeting membrane receptors. It was estimated that half of the marketed mAbs exhibit TMDD (Dirks \& Meibohm, 2010; Mould \& Sweeney, 2007). The actual number is probably higher because the clinical doses at which drugs are studied often saturate the target mediated elimination pathway, thereby masking the nonlinear PK.

At low concentrations TMDD accounts for a significant portion of $\mathrm{mAb}$ clearance. As mAb concentrations increase, target mediated elimination starts to saturate and clearance decreases dramatically. At high mAb concentrations, the clearance approaches a first-order process where the FcRn mediated pathway is dominant and the nonlinear pathway becomes negligible. To determine whether a mAb undergoes TMDD, a single ascending dose iv PK study in a pharmacologically relevant species (in which the mAb binds to the target of interest) is recommended. A typical characteristic of TMDD is readily recognizable by plotting clearance or $t_{1 / 2}$ against dose as depicted in Fig. 4 (Mullamitha et al., 2007).

Nonlinear PK caused by TMDD may have significant consequences on study design (both pre-clinical and clinical), in particular on dose selection, dosing scheme, and sampling times (Dirks \& Meibohm, 2010; Grimm, 2009). Preclinical PK studies with mAb for which TMDD is suspected must be conducted in pharmacologically relevant species (often in NHP) to determine whether the drug is subjected to TMDD. However, the interpretation of the results may be biased by anti-drug antibodies (ADA) interference. It is preferable to conduct a PK study with PD measurement to estimate the exposure and response relationship and to determine whether the PK saturating dose is also the dose at which the PD is saturated. However, it is important to bear in mind that preclinical data can only give a rough estimate of the saturating dose of $a \mathrm{mAb}$ and that findings may not be directly translatable to the clinic. It is generally appreciated that preclinical information is a starting point for designing a clinical TMDD study.

Although TMDD generally occurs more frequently for mAbs that target surface antigens, mAbs against soluble antigens can also exhibit TMDD. For example, Brenner et al. showed that FG-3019, a human mAb against connective tissue growth factor (CTGF) exhibited fast clearance that was determined to be target related. The fast clearance of

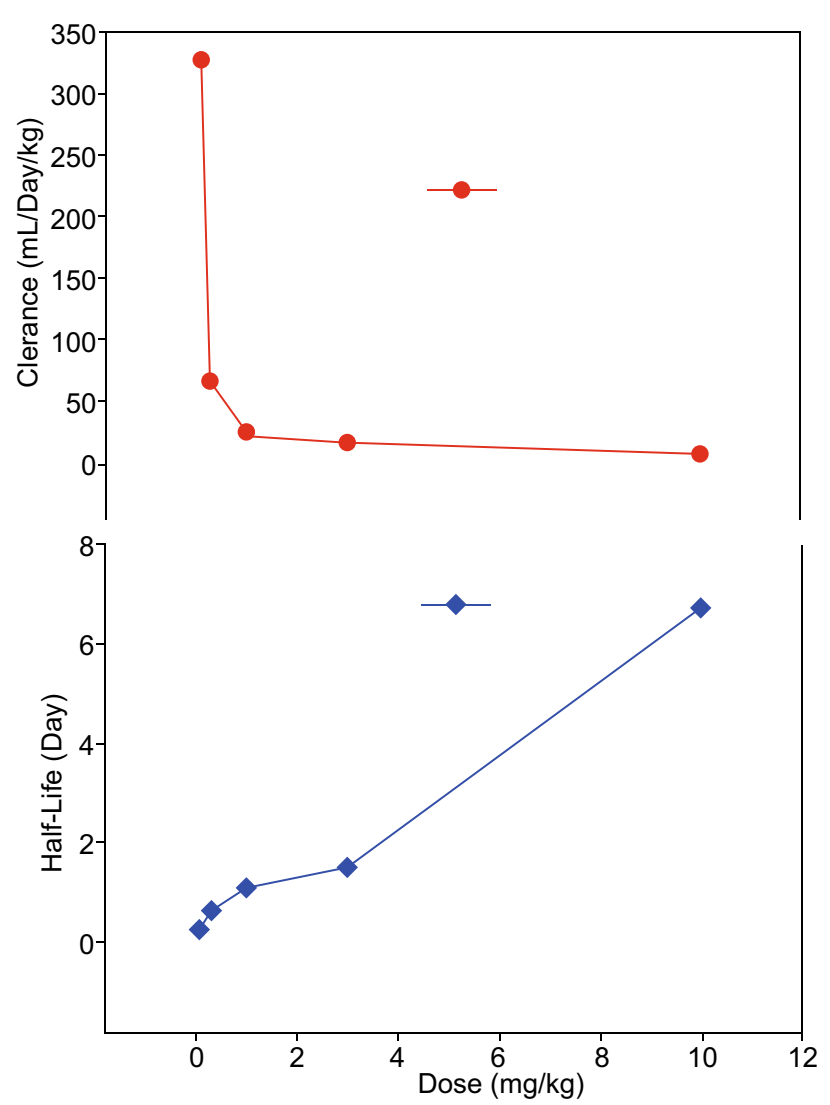

Figure 4. A typical TMDD graph exhibiting the relationship between clearance or $t_{1 / 2}$ and mAb dose. Anti- $\alpha_{v}$ mAb was infused to cancer patients; clearance or terminal half-life $\left(t_{1 / 2}\right)$ was plotted against dose $(0.1,0.3,1$, 3 , and $10 \mathrm{mg} / \mathrm{kg}$ ). Adapted from Mullamitha et al., Clin Cancer Res. (2007).

the FG-3019-CTGF complex was due to the extremely fast clearance of CTGF itself, which is cleared mainly through liver uptake (Brenner et al., 2016).

Because of its assumption of linear disposition, the noncompartmental analysis (NCA) method is inappropriate for PK analysis of drugs with TMDD, except perhaps for initial exploration to uncover or confirm TMDD. While steady state of volume distribution (Vss) can be inferred from blood concentration using NCA for small molecules, Vss for mAb may be underestimated and incorrect if it is derived from NCA analysis or simple compartmental analysis. This is because these models assume linear $\mathrm{PK}$ and rapid equilibrium between blood and tissues (Wang et al., 2008). Therefore, more sophisticated mechanistic models are needed for the TMDD analysis. A general framework of a mechanistic TMDD model was established by Mager and Jusko (2001). Following the base model introduction, several similar models have been developed in several variations (Dua et al., 2015; Gibiansky et al., 2008; Grimm, 2009; Mager, 2006). Information on the target pharmacology, in 
particular its expression and turnover, drug-target binding kinetics, and knowledge of the fate of drug-target complexes, are generally required to build a mechanistic model. However, in most situations, this information is not readily available. For this reason, many analyses use empirical approaches for building models that require less information about the drug target interaction, receptor numbers, and turnover rates (Dua et al., 2015; Gibiansky et al., 2008; Grimm, 2009; Mager, 2006). Nevertheless, in most situations, at least one of the variant models can be useful in modeling a specific mAb's nonlinear behavior.

Based on the model of quasi-steady-state approximations, Grimm thoroughly analyzed the consequences of TMDD on the disposition of mAb (Grimm, 2009). Several conclusions were drawn from this analysis. First, saturation of clearance (from PK analysis) signifies the saturation of the targets when the target is readily accessible. A mAb targeting soluble antigens in the circulation is one example of this situation. Second, when the target is only slowly accessible due to low permeability, saturation of clearance may not imply the saturation of targets, although it may still be used as a proxy for the saturation of the target. Third, when the site of target-mediated clearance and the desired site of action are not the same, especially when the latter is poorly accessible, saturation of clearance no longer implies on-site target saturation. This may occur, for example, when targeting a receptor on a solid tumor which is poorly accessible, and the receptor is also expressed on other normal tissues (such as vascular endothelium) (Grimm, 2009). It has been observed in many cases that in vitro $K_{d}$ of a mAb is often different from the in vivo $K_{\mathrm{d}}$ (or $K_{\mathrm{m}}$ ) obtained from modeling (Brenner et al., 2016; Ng et al., 2006). The in vitro $K_{d}$ often overestimates the affinity of the mAb, likely due to the simplified assay system. The complex situation in vivo can impact the apparent $K_{\mathrm{d}}$ differently (Brenner et al., 2016; $\mathrm{Ng}$ et al., 2006). Other factors such as fast $K_{\text {int }}$ (drug-target internalization rate constant), fast target turnover and limitation of accessibility or permeability also play important roles in drug and target interactions (Grimm, 2009). When choosing clinical candidates, what is the optimum affinity for a mAb? Based on Grimm's analysis, in most cases, optimization of an antibody is a matter of optimizing $K_{\mathrm{m}}$. In certain situations (e.g., $K_{\text {off }} \ll K_{\text {int }}$ ), increasing affinity by decreasing $K_{\text {off }}$ may yield no benefit because of the fast internalization of the target (Grimm, 2009).

\section{Impacts of anti-drug antibody (ADA) on mAb PK}

Most, if not all, therapeutic proteins including mAbs, are immunogenic and can induce ADA in humans. The incidence and the impacts on PK/PD and efficacy vary from drug to drug. Immunogenicity of therapeutic mAbs can cause hypersensitivity responses such as anaphylaxis and infusion reactions, and accelerated clearance of drug, resulting in decreased safety and efficacy (Chirmule et al., 2012).
Both humanized and fully human mAbs can induce ADA in humans; there is no evidence that fully human antibodies are less immunogenic than humanized ones. For example, Humira $^{\circledR}$ (adalimumab), a fully human mAb, induces ADA and impacts PK and efficacy in patients (Bartelds et al., 2011; Chirmule et al., 2012; Harding et al., 2010). Bartelds et al. reported that ADA was developed in $28 \%$ of 272 rheumatoid arthritis (RA) patients who were treated with Humira $^{\circledR}$ for 3 years. RA patients without anti-adalimumab antibodies had much higher adalimumab concentrations (median, $12 \mathrm{mg} / \mathrm{L}$ ) compared with patients with antibody titers from 13 to $100 \mathrm{AU} / \mathrm{mL}$ (median, $5 \mathrm{mg} / \mathrm{L}$ ) (Bartelds et al., 2011). There were significantly more treatment failures that led to the discontinuation of the treatment in patients who developed ADA (Bartelds et al., 2011).

Human $m A b$ or humanized $m A b$ are immunogenic in animals. Van Meer et al. examined the immunogenicity of 27 marketed mAb drugs in NHP and 25 (93\%) developed ADA to the administered mAb (van Meer et al., 2013). ADA can cause perturbation of pharmacokinetic profiles, making it difficult to interpret PK/TK data, particularly when TMDD is suspected. The simplest way to determine the cause of abnormal PK when both ADA and TMDD are the suspects is to measure ADA levels in the serum or plasma of the dosed animals. In most cases, clearance likely coincides with the presence of ADA (Richter et al., 1999). However, the absence of measurable ADA does not mean the absence of ADA especially when the ADA assay sensitivity is low and/or when the drug concentration is above the assay's drug tolerance level (Kelley et al., 2013). Figure 5 shows the typical impact of ADA on the clearance of an administered $\mathrm{mAb}$ drug.

In most cases, ADA occurs mainly in animals exposed to lower doses rather than higher doses. The reason for this phenomenon may be related to high dose induced tolerance (high zone tolerance) (Gilliland et al., 1999; Somerfield et al., 2010) or the interference of high concentrations of mAb in

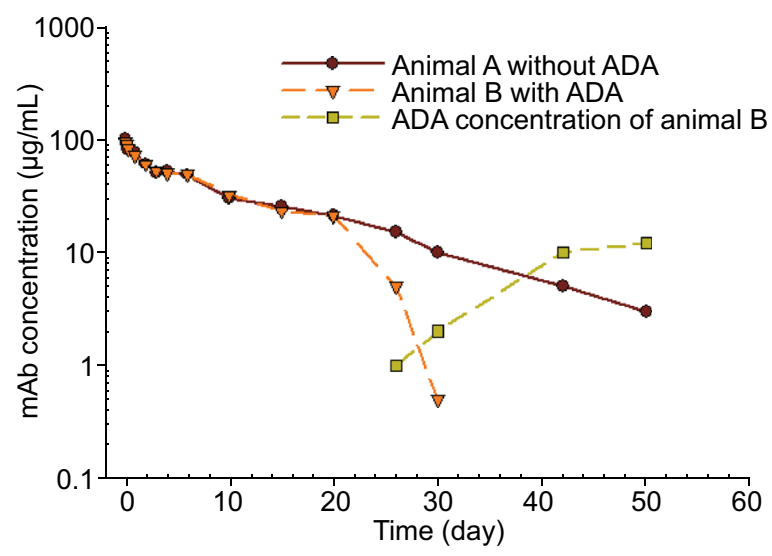

Figure 5. Hypothetical concentration time curves following iv administration of a mAb in animals with or without ADA. 
the serum. Since ADA can lower the exposure of the drug in toxicity species, it is important to use sufficiently high dose levels to achieve desired exposure multiples (based on the anticipated clinical dose). It is also important to take into consideration the ADA assay performance in terms of drug tolerability before declaring a lack of ADA.

The occurrence of ADA of human mAb can be rapid or slow in preclinical animal species. Typically, ADA may appear 2-3 weeks after single dose administration and these are mostly IgG response. In some cases, the occurrence can be even earlier which most likely is mediated by IgM subclass. It is important to note that immunogenicity or ADA response found in preclinical species does not predict ADA response in human (van Meer et al., 2013). It has been reported that the incidence of ADA formation in NHPs and patients was comparable in only $59 \%$ of the cases (van Meer et al., 2013). mAbs can be very immunogenic in animals and yet show no apparent or negligible immunogenicity in humans. Keytruda (pembrolizumab), a humanized IgG4 antiPD1 mAb for the treatment of multiple cancers, is a good example of species differences in ADA formation. Keytruda is quite immunogenic in cynomolgus monkeys as a high incidence of ADA was observed. (BLA\# 125514Orig1s000 Keytruda FDA review package, pharmacology. August 22, 2014; Link http://www.accessdata.fda.gov/drugsatfda_docs/ nda/2014/1255140rig1s000PharmR.pdf).

However, in clinical studies in patients treated with Keytruda $(2 \mathrm{mg} / \mathrm{kg}$ every 3 weeks, $200 \mathrm{mg}$ every 3 weeks, or $10 \mathrm{mg} / \mathrm{kg}$ every 2 or 3 weeks), only $20(1.7 \%)$ of 1,149 evaluable patients tested positive for treatment-emergent anti-pembrolizumab antibodies. There was no evidence of an altered pharmacokinetic profile or increased infusion reactions with anti-pembrolizumab binding antibody development (Highlights of Prescribing Information of Keytruda; Revised: 08/2016. https://www.merck.com/product/usa/pi_ circulars/k/keytruda/keytruda_pi.pdf).

\section{Impacts of off-target binding on mAb PK}

Off-target binding can significantly affect the PK, tissue distribution, efficacy, and toxicity of therapeutic antibodies. Although antibodies developed against an antigen are highly specific to that antigen, some mAbs can have multi-specificity binding capability for irrelevant antigens (James et al., 2003; Notkins, 2004). To prevent autoimmune diseases, antibodies matured through somatic mutations go through stringent control processes in vivo to weed out those unfavorable mutants that bind non-specifically to self-antigen or interact broadly with normal tissues. However, antibodies derived from in vitro selection or maturation lack an in vivolike control system and rely on the counter screen to ensure specificity. This can lead to the selection of some nonspecifically binding variants. For example, the A4B4 variant, (a prototype of Motavizumab, which is an in vitro affinity matured anti-RSV mAb derived from palivizumab), demonstrated broad tissue binding and accelerated clearance in vivo (Wu et al., 2007). Multiple off-target interactions were demonstrated on protein biochips for adalimumab, which was derived in vitro from a cloned human antibody phage library (Feyen et al., 2008).

Recently, Datta-Mannan et al. showed that bispecific IgGSCFv or IgG-ECD antibodies were cleared rapidly through liver sinusoidal endothelial cells (LSEC) in the liver (DattaMannan et al., 2016). The rapid clearance of BsAb was not attributed to TMDD, reduced Fc-FcRn interaction, or poor molecular or biochemical properties. Instead it was due to non-specific binding or association with LSEC. mAbs may also bind specifically to a non-intended target and cause alteration of PK/PD and toxicity profiles. Bumbaca et al. reported that a humanized mAb (hLD1.vB) directed against fibroblast growth factor receptor (FGFR) 4 exhibited specific binding to mouse complement component 3 (C3), leading to accelerated clearance and limited efficacy in mice (Bumbaca et al., 2011). Vugmeyster et al. also reported that an antimonkey A-beta mAb had off-target binding in cynomolgus monkeys, leading to accelerated clearance (Vugmeyster et al., 2011).

Because the unpredictability of the off-target binding, it is recommended that $\mathrm{mAb}$ candidates go through early screens for non-target bindings in vitro including protein microarrays, light directed peptide synthesis arrays, and tissue cross-reactivity assays (Kelly et al., 2015; Hotzel et al., 2012b). These screens, along with preclinical evaluation in rodents and primates, are important tools in the assessment of how well a mAb will behave in the clinic. Hotzel et al. reported a strategy for mitigation of risk for antibodies with fast clearance. It is an assay based on ELISA detection of non-specific binding to baculovirus particles that can identify antibodies having increased risk for fast clearance (Hotzel et al., 2012b). This assay can be used during lead generation or optimization to identify antibodies with increased risk of having fast clearance in both humans and cynomolgus monkeys, thus increasing the likelihood of obtaining a suitable drug candidate. Recently high throughput cross-interaction assays were developed to screen mAbs for off-target mediated clearance. These assays showed high correlation with clearance rate in mice (Kelly et al., 2015). Others used protein and/or tissue arrays to determine cross reactivity of mAbs (Lueking et al., 2008; Kijanka et al., 2009).

\section{MAB ABSORPTION}

The majority of FDA-approved therapeutic antibodies are administered intravenously (iv). The iv route allows for rapid delivery of large amounts of antibodies to the systemic circulation with complete systemic availability. In addition, the iv route allows the administration of larger volumes in comparison to other parenteral routes of administration. However, iv delivery, often required to be conducted in hospitals or doctor's office, is not convenient for patients, and increases the cost of therapy. In addition, rapid infusion of 
antibody may also induce adverse events such as infusion reactions. Therefore, for some mAbs requiring chronic dosing, extravascular routes such as subcutaneous (sc) and intra-muscular (im) administration have been developed. Sc or im administration can be performed by a health care professional in a patient's home or even by self-administration (Richter \& Jacobsen, 2014). Examples for extravascular administration of $\mathrm{mAbs}$ or $\mathrm{Fc}$ fusions are adalimumab (sc), alefacept (im), efalizumab (sc), etanercept (sc), omalizumab (sc), and palivizumab (im).

The systemic absorption of antibodies following sc or im administration most likely occurs via the lymphatic system. The highly porous lymphatic system allows the transport of macromolecules (>20 kDa MW) through the convective flow of the interstitial fluids (Richter et al., 2012; Richter \& Jacobsen, 2014). Since the lymph fluid drains slowly into the vascular system, the absorption of antibodies from the site of administration usually continues for hours or even days (Richter et al., 2012). In animals and in man, the time to maximal plasma concentrations ( $\mathrm{T}_{\max }$ ) of antibody are typically observed 1-8 days following sc or im administration (Lobo et al., 2004). In general, antibodies given by im or sc are well absorbed, resulting in bioavailabilities ranging from $50 \%$ to $100 \%$ (Richter \& Jacobsen, 2014). There is no correlation between MW and the bioavailability of protein therapeutics in several animal species and in humans (Richter et al., 2012).

The extent of absorption of mAbs can be variable depending on the extent of pre-systemic antibody degradation including proteolytic degradation, endocytosis at the injection site and rates of recycling through interaction with FcRn (Wang et al., 2008). The absorption of therapeutic proteins can also be impacted by formulation and injection volumes (Richter et al., 2012; Richter \& Jacobsen, 2014). In addition, physiologic factors such as age, body weight, movement, heat, and injection site may also serve as covariates for the bioavailability of therapeutic proteins including mAbs (Richter \& Jacobsen, 2014). It was observed that fat content and physical activities can profoundly impact the absorption of therapeutic proteins in an animal model (Wang et al., 2012). Sc absorption rates in animals appear to be more rapid than in humans. Non-human primates tend to overestimate the sc bioavailability of mAbs and rodent and several other preclinical species do not appear to exhibit any clear patterns in relationship to humans (Richter et al., 2012). Recently the minipig was suggested as a potential translatable model for mAb pharmacokinetics following iv or sc administration (Zheng et al., 2012).

Large doses may not be feasible for sc or im administration due to the relatively limited solubility of $\operatorname{lgG}(\sim 100 \mathrm{mg} / \mathrm{mL})$; small volumes can be administered via these routes (2.5 or $5 \mathrm{~mL}$ for sc and im per site, respectively) (Richter et al., 2012). For mAbs requiring relatively low dose, such as Humira (40 mg/dose), sc administration can be easily achieved at $40 \mathrm{mg} / 0.8 \mathrm{~mL}$ injection pen (Humira ${ }^{\circledR} \mathrm{PI}$ ). However, for mAbs requiring high doses, such as omalizumab, multiple injection sites are necessary; a dose of $375 \mathrm{mg}$ is delivered via three separate $1 \mathrm{~mL} s c$ injections (Xolair PI). More recently, the limitation of volume in sc administration of mAb appears to have been ameliorated by including hyaluronidase in the formulation. In the subcutaneous space, the glycosaminoglycan hyaluronan, together with collagen, creates a volume barrier within the extracellular matrix (Bookbinder et al., 2006). Hyaluronan can be degraded by hyaluronidase and hyaluronidase derived from animal testes has been used extensively to facilitate dispersion of co-injected materials in the clinic (Bookbinder et al., 2006). With co-formulation of hyaluronidase, it is now clinically feasible to administer mAb's for oncology indications which typically require much larger doses and volumes (Jackisch et al., 2014; Salar et al., 2014; Shpilberg \& Jackisch, 2013). rHuPH20, a recombinant hyaluronidase temporarily cleaving hyaluronan fibers in the interstitial tissue, and thereby facilitating the sc injection of large volumes, has been used to co-formulate several important anti-cancer mAbs. With co-formulation with hyaluronidae, it is now possible to administer volumes up to $5 \mathrm{~mL} \mathrm{sc}$ in approximately $5 \mathrm{~min}$ for $600 \mathrm{mg}$ trastuzumab (Bittner et al., 2012). Rituximab can be delivered in 2-8 min with 4.4$15.0 \mathrm{~mL}$ sc (Salar et al., 2014). A fixed dose of $1,400 \mathrm{mg}$ of rituximab was successfully delivered via sc injection by hyperconcentrating rituximab (12-fold) relative to the IV formulation and including the rHuPH20 as an excipient in a volume of $11.7 \mathrm{~mL}$ (Salar et al., 2014; Shpilberg \& Jackisch, 2013). The $C_{\text {trough }}$ of sc delivered $m A b$ was not inferior to that delivered by IV at $375 \mathrm{mg} / \mathrm{m}^{2}$ (Salar et al., 2014). Sc administration is also generally more immunogenic than drug dosed via the IV route. For example, anti-trastuzumab antibodies were detected in 8 of the 58 patients who received trastuzumab sc compared to zero of the 12 patients who received trastuzumab IV. That said, the presence of anti-trastuzumab antibodies did not correlate with the adverse events and pharmacokinetic profiles in these patients (Wynne et al., 2013). In EU, sc formulation for rituximab was approved for NHL (1,400 mg) in 2014 and for CLL (1,600 mg) in 2016 (Roche Media Release, 2016). Herceptin sc formulation (600 mg) for breast cancer was approved in EU in 2013 (Roche Media Release, 2013).

\section{MAB DISTRIBUTION}

Being large and polar molecules, antibodies move very slowly across vascular endothelial cells. Convection is believed to be the primary mechanism responsible for the transport of antibody from blood to the interstitial space of tissues (Richter \& Jacobsen, 2014). The rate of convection out of the blood and the rate of antibody catabolism within tissue determine the rate of antibody elimination. In general, antibody concentrations in tissue interstitial fluid are substantially lower than antibody concentrations in plasma because of the differences in the rate of convective uptake (which is slow) and elimination of antibody from tissue (which could be fast). However, higher antibody concentrations 
have been observed in tissues that are highly perfused and with relatively leaky vasculature (e.g., bone marrow, spleen, and liver). IgG antibodies show very little distribution to the brain because of blood brain barrier. Shah and Betts conducted analyses of bio-distribution data of non-binding mAbs from several different species (mice, rat, monkey, and human). Using a physiologically based pharmacokinetic (PBPK) model, they were able to define the relationship between plasma and various tissue concentrations as the antibody biodistribution coefficient (ABC). They found that typically the concentration of $\mathrm{mAb}$ in lung is $15 \%$, heart $10 \%$, kidney $14 \%$, muscle $4 \%$, skin $16 \%$, small intestine $5 \%$, large intestine $5 \%$, spleen $13 \%$, liver $12 \%$, bone $7 \%$, stomach $5 \%$, lymph node $8 \%$, adipose $5 \%$, brain $0.4 \%$, pancreas $6 \%$, testes $6 \%$, thyroid $68 \%$, and thymus $7 \%$ of the plasma concentration (Shah \& Betts, 2013). These results are consistent with the general estimates of tissue to blood ratio range of 0.1 to 0.5 for mAbs (Lobo et al., 2004). However, it is important to point out that most of the tissue distribution data were obtained with iodine labeled mAbs and unusually high distribution to thyroid should be interpreted with caution because of the concentration effect of iodine-labeled metabolites in the thyroid.

In cases where an antibody shows high-affinity, high-capacity binding to tissue and target-mediated elimination, the true Vss may be much greater than the distribution volume estimated by standard NCA analysis. It was reported that a $\mathrm{mAb}$ against keratin sulfate exhibited much higher tissue concentrations than in the plasma with tissue to blood ratio being 5.9, 4.3, 3.5, and 2.6 for lung, esophagus, kidney, and liver, respectively (Kairemo et al., 2001). Similarly, some mAbs directed against endothelial antigens also showed very high tissue to blood ratios. For example, a tissue distribution study showed that the lung-to-blood ratio was 5,10 , and 15 for antibodies of anti-Thy-1.1, anti-ACE, and antiICAM-1, respectively (Danilov et al., 2001). It is worth noting that the non-binding IgG typically has a tissue to blood ratio ranging from 0.04 to 0.68 (Shah \& Betts, 2013).

In a modeling study comparing antibodies with different affinities in distribution to tumors, Fujimori et al. observed that the average antibody concentration in the tumor does not increase linearly with affinity. High antibody affinity at a given dose tends to decrease antibody percolation or penetration to the tumor because the high affinity binding to the edge of the tumor leads to fewer free antibody molecules. This phenomenon was termed "binding site barrier" (Fujimori et al., 1990). Using mAbs that recognize the same Her2 epitope but with different affinities $(270,23,7.3$, and $0.56 \mathrm{nmol} / \mathrm{L})$, Rudnick et al. confirmed the "binding site barrier" phenomenon in vivo. They reported that moderate affinity was associated with the highest tumor accumulation at $24 \mathrm{~h}$ and $120 \mathrm{~h}$ after intravenous injection. High affinity was found to produce low tumor accumulation (Rudnick et al., 2011) (Fig. 6). Similar results were obtained recently in a tumor distribution study by Glatt et al. with anti-CD44 antibodies of different affinities (Glatt et al., 2016).

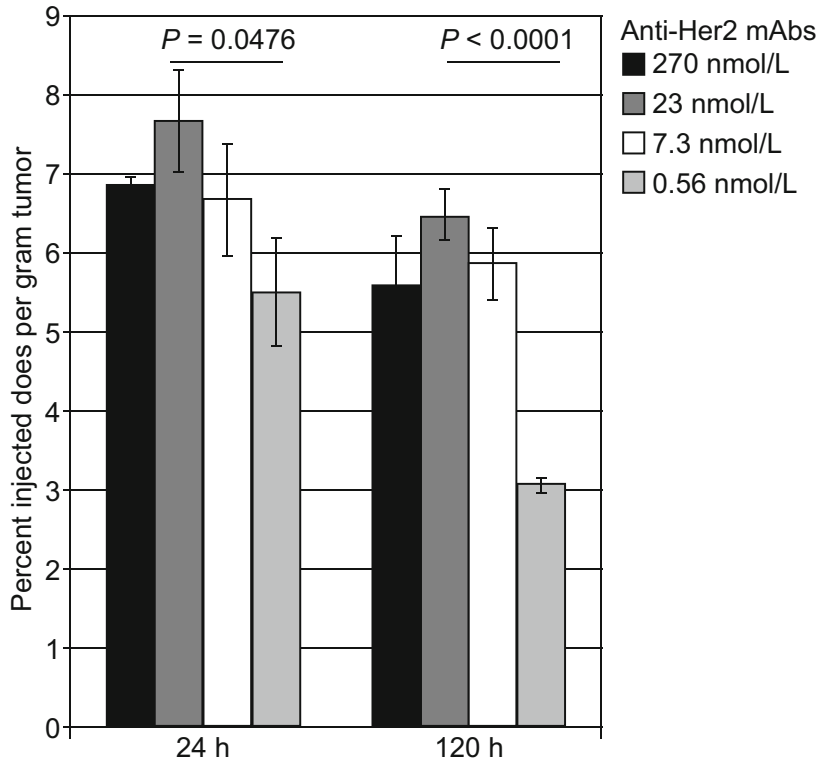

Figure 6. Tumor distribution of anti-Her2 mAbs with different affinities. Adapted from Rudnick et al. (2011).

Zahnd et al. used Darpins, a $14.5 \mathrm{kDa}$ target binding protein to systemically evaluate the size and affinity effects on the tumor distribution. Darpins of different size (with or without Pegylation) and affinity against HER2 were tested in tumor tissue distribution studies. The results showed that for small proteins like Darpin that were eliminated rapidly by kidney filtration, improving affinity directly improved tumor uptake. However, for large targeting agents like Pegylated Darpin, the impact of affinity on tumor accumulation is diminished. The dependence of tumor uptake on binding affinity was found to be weak once $K d<100 \mathrm{nmol} / \mathrm{L}$ (Wittrup et al., 2012; Zahnd et al., 2010). scFvs, Fabs, diabodies, darpins, and the like are considered too large for sufficiently rapid extravasation and too small to escape renal clearance. Whole IgG antibody is considered to be the optimal size for tumor targeting (Wittrup et al., 2012).

$\mathrm{mAb}$ accessibility to tissues can also be observed in PD readouts. In a monkey distribution study with rituximab, the levels of peripheral blood B cells were already depleted by $>94 \% 2$ days after the first dose and 9 days after the second dose. However, B cell levels in lymph nodes were only decreased by $42 \%-57 \%$ at 9 days following the 2 nd dose (Mao et al., 2013). These results indicate that solid tissues are more difficult to penetrate by $\mathrm{mAb}$ and the "binding site barrier" could restrict the distribution of mAb, leading to a delayed pharmacological effect in the tissues.

\section{HUMAN PK PREDICTION AND FIRST IN HUMAN STARTING DOSE SELECTION}

PK parameters of small molecule drugs can be scaled across species using a power model of the form $Y=a^{*} B W^{b}$ with reasonable accuracy (Huang \& Riviere, 2014; Wang 
Figure 7. Relationship between MABEL, NOAEL, therapeutic window and toxicity in FIH trial. MABEL: minimally anticipated biological effect level; NOAEL: no observed adverse effect level. Modified from Muller et al., Curr Opin Biotechnol. (2009).

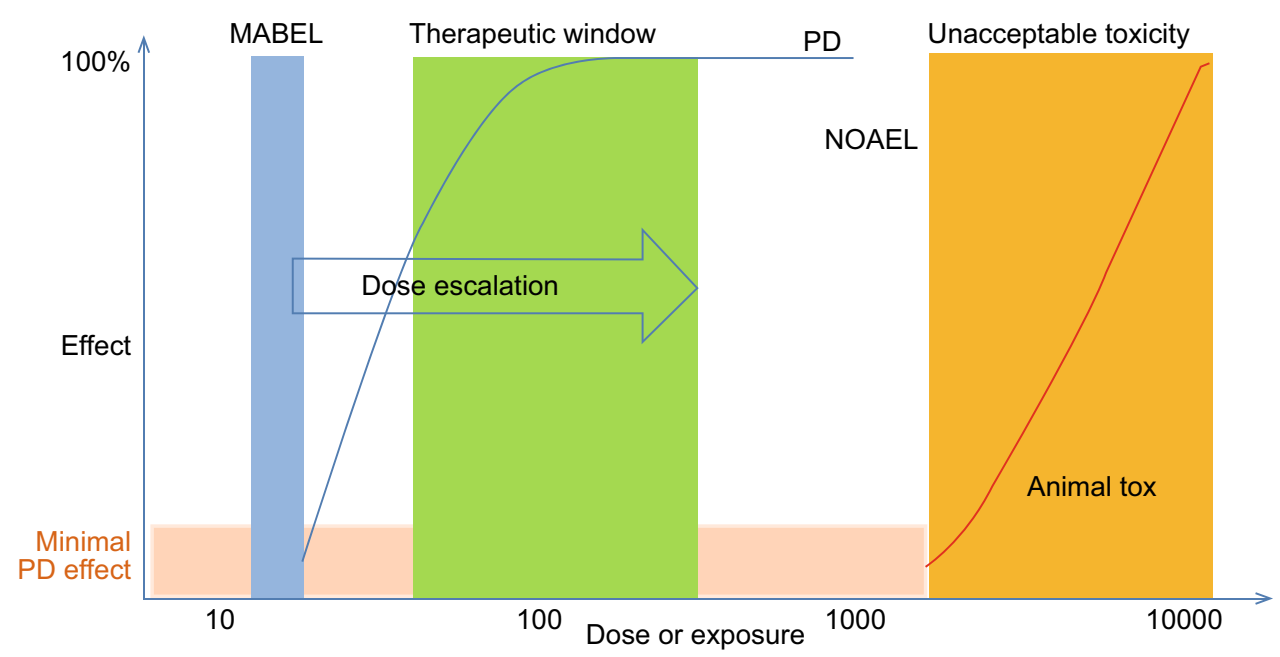

et al., 2016). This equation is based on the principle of allometry; $\mathrm{Y}$ is the parameter of interest (e.g., clearance or volume); $a$ is the allometric coefficient; BW is the body weight; $b$ is the allometric exponent. For large molecules such as mAbs with nonlinear PK, assumptions underlying allometric scaling, such as the absence of nonlinear pharmacokinetics and species-specific clearance may not be correct. Nevertheless, in many cases, PK parameters of mAbs with non-target related elimination pathways or doses above the target saturation levels in humans can be reasonably predicted using data from cynomolgus monkeys with an allometric exponent of $\sim 0.85$ (Deng et al., 2011; Dong et al., 2011; Ling et al., 2009; Wang \& Prueksaritanont, 2010). Different exponents were proposed for reasonable predictions of human $\mathrm{CL}$ and Vss for $24 \mathrm{mAbs}$ targeting either soluble antigen or membrane receptors (Oitate et al., 2011). By analyzing data from preclinical and clinical studies of 13 therapeutic mAbs, Deng et al. showed that $C L$ of mAbs can be better predicted based on cynomolgus PK data and an allometric scaling exponent of 0.85 . Human concentration-time profiles were also reasonably predicted from the cynomolgus monkey data using species-invariant time method with a fixed exponent of 0.85 for $\mathrm{CL}$ and 1.0 for volume of distribution (Deng et al., 2011). A relatively higher accuracy prediction for pharmacokinetics in humans may be achieved by physiologically based PBPK modeling that has the advantage of allowing prediction of antibody levels in many tissues, including tumors. It also takes into consideration the effects of saturable processes (e.g., target binding, FcRn recycling) on antibody $\mathrm{PK}$ and the impacts of a variety of other factors (e.g., antigen expression, antibody affinity) on the tissue selectivity of antibody disposition (Shah \& Betts, 2013; Wang et al., 2016). However, PBPK models are complex, mathematically difficult to construct, poorly suited to population analyses, and often limited because of a lack of tissue concentration data, parameter availability, or parameter identifiability (Shah \& Betts, 2013; Wang et al., 2016). Although the drug exposure in humans can be reasonably predicted for mAbs with linear PK above saturation dose, prediction of drug exposure at low starting doses for mAbs (typically starting dose for dose escalation study) is challenging and generally poor because of nonlinear PK (Dong et al., 2011). Further exploration of species differences in the target expression level, target-antibody binding and target kinetics, and in vivo PK studies with relevant dose ranges may help to solve this issue.

For oncology indications, rule based standard $3 \times 3$ dose escalation methods have been used for most mAb FIH studies. This scheme is to ensure safety and tolerability in $\mathrm{FIH}$ trials. Several approaches coexisted that are frequently used in FIH dose predictions. The classic approach for determining the maximum recommended starting dose (MRSD) is based on the no observed adverse effect level (NOAEL) dose determination from toxicity studies and subsequent human equivalent dose (HED) estimation according to the FDA Guidance (2005). Minimally anticipated biological effect level (MABEL) is EMA's response to the TGN-1412 disaster which was not predicted with the classical method (EMEA, 2007; Muller et al., 2009; UK Expert Scientific Group, 2006). This approach had been specifically designed for 'high-risk medicinal products' with, for example, novel mechanisms of action or high species specificity. Figure 7 graphically depicts the relationship between MABEL, NOAEL, and starting dose. Currently, most clinical development programs use combinations of several or all available approaches to seek 'totality of evidence' to develop a $\mathrm{FIH}$ dose selection rationale for a particular mAb-based therapeutics. The totality of evidence may include the exposure-response relationships, receptor-occupancy in relationship to efficacy and biological effects and HED based on NOAEL. The MOA should be taken into consideration as well. For example, agonistic or modulator of immune system (high risk) mAbs starting dose should be considered differently from antagonist antibodies. Extreme care should be given to immune agonist antibodies whereas antagonists can generally be tolerated relatively higher starting dose 
(Luu et al., 2013; Muller et al., 2009). For mAbs that are not considered high-risk biologics, usually antagonist (blocking) mAbs, the MABEL approach may not be required. However, it may still be useful to rationally select the starting human dose from a pharmacological standpoint relative to a toxicological standpoint (Luu et al., 2013). Recently, an FDA oncology analysis of immune activating products and first-inhuman dose selection by Saber et al. reinforced the concepts discussed above on the totality of data for considering $\mathrm{FIH}$ doses of immune activating biologics (Saber et al., 2016). Importantly, the FDA authors pointed out that while evaluating safe dose is the primary goal of FIH trial, subtherapeutic doses are not medically justifiable in patients with cancer; therefore, optimization of the $\mathrm{FIH}$ trial designs to allow rapid attainment of active therapeutic doses is also important (Saber et al., 2016).

Traditionally, doses of therapeutic mAbs are generally chosen based on body weight. Recently, fixed dosing of mAb is gaining popularity because of dosing convenience in medical practice. The specificity of $m A b s$, a relatively large therapeutic window and generally a small contribution of body size to pharmacokinetic variability favor fixed dosing of mAbs (Bai et al., 2012; Wang et al., 2009). Using modeling and simulation to compare the PK variations of body weight based dosing vs. fixed dosing, Bai et al. demonstrated that, for most mAbs, body weight had little or moderate effect on PK. The difference of variability in exposure between body weight-based and fixed dosing was generally less than $20 \%$, which is moderate relative to the variability generally observed in pharmacodynamics, efficacy, and safety (Bai et al., 2012). Given the many practical advantages, fixed dosing is generally recommended for FIH studies with mAbs. The dosing strategy in later stages of clinical development could then be determined based on combined knowledge of the body weight effect on pharmacokinetics, safety, and efficacy observed in the early clinical trials (Bai et al., 2012; Wang et al., 2009). For those mAbs that exhibit TMDD and nonlinear pharmacokinetics, loading or 'induction' dose strategies may be appropriate to saturate or clear available antigen targets. For example, Herceptin (trastuzumab) has a loading dose of $4 \mathrm{mg} / \mathrm{kg}$ loading dose followed by $2 \mathrm{mg} / \mathrm{kg}$ weekly dose (Herceptin PI).

\section{CONCLUSIONS}

This review article discusses current understanding of PK of therapeutic $m A b$ and $\mathrm{Fc}$-fusion proteins. As a large and polar molecule, mAb and Fc-fusion molecules have PKs that are substantially different from that of small molecule drugs. FcRn mediated recycling is the primary determinant of an IgG antibody's PK properties. Through Fab and/or Fc engineering, IgG-FcRn interactions can be used to generate a variety of therapeutic antibodies with significantly enhanced half-life or the ability to remove unwanted antigen from circulation (sweeping antibody). Glycosylation on mAb or Fcfusion protein can have a significant impact on the $\mathrm{PK}$ of these molecules. High mannose content is a liability for mAb and sialic acids are beneficial to Fc-fusion proteins. mAb charge can also be important. Variation of pl values by 1-2 units is likely to impact $\mathrm{PK}$, with lower pl values being favorable. In contrast to small molecule drugs, most mAbs display TMDD. This can have significant consequences on study design (both pre-clinical and clinical), in particular on dose selection, dosing scheme, and sampling times. The PK of $\mathrm{mAb}$ can also be influenced by anti-drug antibody (ADA) response and off-target binding, which require careful consideration during the discovery stage. $\mathrm{mAb}$ is primarily absorbed through the lymphatic system and can be conveniently administered by sc dosing. Large doses or volumes can be administered with hyaluronidase co-formulation. mAb slowly distributes to the interstitial space of tissues via convection. This results in a tissue to blood ratio ranging from $0.1-0.5$, although the value can be significantly higher than 1 with $\mathrm{mAb}$ showing high-affinity and high-capacity binding in tissues. PK parameters of $\mathrm{mAb}$ with linear PK (above the target saturation dose) in humans can be reasonably predicted by using data from cynomolgus monkeys and an allometric exponent of $\sim 0.85$. Combination of several methods such as NOAEL and MABEL should be considered for prediction of $\mathrm{FIH}$ starting dose. In some situation, fixed dose is possible in humans if body size and weight do not contribute significantly to PK variability.

\section{ACKNOWLEDGEMENTS}

I am very grateful for the valuable inputs and discussions provided by Drs. Raymond Evers, Kapil Mayawala, Brian Topp, Anson Abraham, Tommy Ruosi Li, and lain Martin.

\section{ABBREVIATIONS}

$A B C$, antibody biodistribution coefficient; $A D A$, anti-drug antibody; $A D C C$, antibody dependent cell-mediated cytotoxicity; ADCs, antibody-drug conjugates; ASGPR, asialoglycoprotein receptor; C3, complement component 3; CDC, complement dependent cytotoxicity; CQA, critical quality attributes; CTGF, connective tissue growth factor; FcRn, neonatal Fc receptor; FGFR, fibroblast growth factor receptor; HED, human equivalent dose; im, intra-muscular; LSEC, liver sinusoidal endothelial cells; mAb, monoclonal antibody; MABEL, minimally anticipated biological effect level; ManR, mannose receptor; MRSD, maximum recommended starting dose; NCA, non-compartmental analysis; NOAEL, no observed adverse effect level; PBPK, physiologically based pharmacokinetic; PD, pharmacodynamics; pl, isoelectric point; $\mathrm{PK}$, pharmacokinetics; sc, subcutaneous; $\mathrm{T}_{\max }$, maximal plasma concentrations; TMDD, target mediated drug disposition; Vss, steady state of volume distribution

\section{OPEN ACCESS}

This article is distributed under the terms of the Creative Commons Attribution 4.0 International License (http://creativecommons.org/ licenses/by/4.0/), which permits unrestricted use, distribution, and reproduction in any medium, provided you give appropriate credit to 
the original author(s) and the source, provide a link to the Creative Commons license, and indicate if changes were made.

\section{REFERENCES}

Abuqayyas L, Zhang X, Balthasar JP (2013) Application of knockout mouse models to investigate the influence of FcgammaR on the pharmacokinetics and anti-platelet effects of MWReg30, a monoclonal anti-GPIlb antibody. Int J Pharm 444:185-192

Alt N, Zhang TY, Motchnik P, Taticek R, Quarmby V, Schlothauer T, Beck H, Emrich T, Harris RJ (2016) Determination of critical quality attributes for monoclonal antibodies using quality by design principles. Biologicals 44:291-305

Arnold JN, Wormald MR, Sim RB, Rudd PM, Dwek RA (2007) The impact of glycosylation on the biological function and structure of human immunoglobulins. Annu Rev Immunol 25:21-50

Ashwell G, Harford J (1982) Carbohydrate-specific receptors of the liver. Annu Rev Biochem 51:531-554

Bai S, Jorga K, Xin Y, Jin D, Zheng Y, Damico-Beyer LA, Gupta M, Tang M, Allison DE, Lu D, Zhang Y, Joshi A, Dresser MJ (2012) A guide to rational dosing of monoclonal antibodies. Clin Pharmacokinet 51:119-135

Bartelds GM, Krieckaert CL, Nurmohamed MT, van Schouwenburg PA, Lems WF, Twisk JW, Dijkmans BA, Aarden L, Wolbink GJ (2011) Development of antidrug antibodies against adalimumab and association with disease activity and treatment failure during long-term follow-up. JAMA 305:1460-1468

Bertolotti-Ciarlet A, Wang W, Lownes R, Pristatsky P, Fang Y, McKelvey T, Li Y, Li Y, Drummond J, Prueksaritanont T, Vlasak J (2009) Impact of methionine oxidation on the binding of human IgG1 to Fc Rn and Fc gamma receptors. Mol Immunol 46:18781882

Bittner B, Richter WF, Hourcade-Potelleret F, Mclntyre C, Herting F, Zepeda ML, Schmidt J (2012) Development of a subcutaneous formulation for trastuzumab-nonclinical and clinical bridging approach to the approved intravenous dosing regimen. Arzneimittelforschung 62:401-409

Bookbinder LH, Hofer A, Haller MF, Zepeda ML, Keller GA, Lim JE, Edgington TS, Shepard HM, Patton JS, Frost GI (2006) A recombinant human enzyme for enhanced interstitial transport of therapeutics. J Control Release 114:230-241

Boswell CA, Tesar DB, Mukhyala K, Theil FP, Fielder PJ, Khawli LA (2010) Effects of charge on antibody tissue distribution and pharmacokinetics. Bioconjug Chem 21:2153-2163

Brambell FW (1966) The transmission of immunity from mother to young and the catabolism of immunoglobulins. Lancet 2:10871093

Brambell FW, Hemmings WA, Morris IG (1964) A theoretical model of gamma-globulin catabolism. Nature 203:1352-1354

Brenner MC, Krzyzanski W, Chou JZ, Signore PE, Fung CK, Guzman D, Li D, Zhang W, Olsen DR, Nguyen VT, Koo CW, Sternlicht MD, Lipson KE (2016) FG-3019, a human monoclonal antibody recognizing connective tissue growth factor, is subject to target-mediated drug disposition. Pharm Res 33:1833-1849

Bumbaca D, Wong A, Drake E, Reyes AE, Lin BC, Stephan JP, Desnoyers L, Shen BQ, Dennis MS (2011) Highly specific off- target binding identified and eliminated during the humanization of an antibody against FGF receptor 4. MAbs 3:376-386

Bumbaca D, Boswell CA, Fielder PJ, Khawli LA (2012) Physiochemical and biochemical factors influencing the pharmacokinetics of antibody therapeutics. AAPS J 14:554-558

Bumbaca YD, Sharma VK, Boswell CA, Hotzel I, Tesar D, Shang Y, Ying Y, Fischer SK, Grogan JL, Chiang EY, Urban K, Ulufatu S, Khawli LA, Prabhu S, Joseph S, Kelley RF (2015) Evaluating the use of antibody variable region (Fv) charge as a risk assessment tool for predicting typical cynomolgus monkey pharmacokinetics. J Biol Chem 290:29732-29741

Challa DK, Bussmeyer U, Khan T, Montoyo HP, Bansal P, Ober RJ, Ward ES (2013) Autoantibody depletion ameliorates disease in murine experimental autoimmune encephalomyelitis. MAbs 5:655-659

Chen X, Liu YD, Flynn GC (2009) The effect of Fc glycan forms on human $\lg \mathrm{G} 2$ antibody clearance in humans. Glycobiology 19:240-249

Chirmule N, Jawa V, Meibohm B (2012) Immunogenicity to therapeutic proteins: impact on PK/PD and efficacy. AAPS J 14:296302

Clarke S, Gebbie C, Sweeney C, Olszewksi N, Smith J. A phase I, pharmacokinetic (PK) and preliminary efficacy assessment of ALD518, a humanized anti-IL-6 antibody, in patients with advanced cancer. 2009 ASCO poster. 2009. Ref Type: Abstract

Daëron C (2014) Fc receptors as adaptive immunoreceptors. Curr Top Microbiol Immunol 382:131-164

Danilov SM, Gavrilyuk VD, Franke FE, Pauls K, Harshaw DW, McDonald TD, Miletich DJ, Muzykantov VR (2001) Lung uptake of antibodies to endothelial antigens: key determinants of vascular immunotargeting. Am J Physiol Lung Cell Mol Physiol 280:L1335-L1347

Datta-Mannan A, Wroblewski VJ (2014) Application of FcRn binding assays to guide mAb development. Drug Metab Dispos 42:18671872

Datta-Mannan A, Witcher DR, Tang Y, Watkins J, Jiang W, Wroblewski VJ (2007a) Humanized IgG1 variants with differential binding properties to the neonatal Fc receptor: relationship to pharmacokinetics in mice and primates. Drug Metab Dispos 35:86-94

Datta-Mannan A, Witcher DR, Tang Y, Watkins J, Wroblewski VJ (2007b) Monoclonal antibody clearance. Impact of modulating the interaction of $\mathrm{IgG}$ with the neonatal Fc receptor. J Biol Chem 282:1709-1717

Datta-Mannan A, Chow CK, Dickinson C, Driver D, Lu J, Witcher DR, Wroblewski VJ (2012a) FcRn affinity-pharmacokinetic relationship of five human IgG4 antibodies engineered for improved in vitro FcRn binding properties in cynomolgus monkeys. Drug Metab Dispos 40:1545-1555

Datta-Mannan A, Witcher DR, Lu J, Wroblewski VJ (2012b) Influence of improved FcRn binding on the subcutaneous bioavailability of monoclonal antibodies in cynomolgus monkeys. MAbs 4:267-273

Datta-Mannan A, Croy JE, Schirtzinger L, Torgerson S, Breyer M, Wroblewski VJ (2016) Aberrant bispecific antibody pharmacokinetics linked to liver sinusoidal endothelium clearance mechanism in cynomolgus monkeys. MAbs 8:969-982 
Deng R, Loyet KM, Lien S, lyer S, DeForge LE, Theil FP, Lowman HB, Fielder PJ, Prabhu S (2010) Pharmacokinetics of humanized monoclonal anti-tumor necrosis factor-\{alpha\} antibody and its neonatal $\mathrm{Fc}$ receptor variants in mice and cynomolgus monkeys. Drug Metab Dispos 38:600-605

Deng R, lyer S, Theil FP, Mortensen DL, Fielder PJ, Prabhu S (2011) Projecting human pharmacokinetics of therapeutic antibodies from nonclinical data: what have we learned? MAbs 3:61-66

Dirks NL, Meibohm B (2010) Population pharmacokinetics of therapeutic monoclonal antibodies. Clin Pharmacokinet 49:633659

Dong JQ, Salinger DH, Endres CJ, Gibbs JP, Hsu CP, Stouch BJ, Hurh E, Gibbs MA (2011) Quantitative prediction of human pharmacokinetics for monoclonal antibodies: retrospective analysis of monkey as a single species for first-in-human prediction. Clin Pharmacokinet 50:131-142

Dua P, Hawkins E, van der Graaf PH (2015) A tutorial on targetmediated drug disposition (TMDD) models. CPT Pharmacomet Syst Pharmacol 4:324-337

Ecker DM, Jones SD, Levine HL (2015) The therapeutic monoclonal antibody market. MAbs 7:9-14

Elvin JG, Couston RG, van der Walle CF (2013) Therapeutic antibodies: market considerations, disease targets and bioprocessing. Int J Pharm 440:83-98

EMEA (2007) Guideline on requirements for first-in-man clinical trials for potential high-risk medicinal products. Ref Type: Pamphlet

Fasanmade AA, Adedokun OJ, Olson A, Strauss R, Davis HM (2010) Serum albumin concentration: a predictive factor of infliximab pharmacokinetics and clinical response in patients with ulcerative colitis. Int J Clin Pharmacol Ther 48:297-308

Feyen O, Lueking A, Kowald A, Stephan C, Meyer HE, Gobel U, Niehues T (2008) Off-target activity of TNF-alpha inhibitors characterized by protein biochips. Anal Bioanal Chem 391:1713-1720

Fujimori K, Covell DG, Fletcher JE, Weinstein JN (1990) A modeling analysis of monoclonal antibody percolation through tumors: a binding-site barrier. J Nucl Med 31:1191-1198

Gao X, Ji JA, Veeravalli K, Wang YJ, Zhang T, Mcgreevy W, Zheng K, Kelley RF, Laird MW, Liu J, Cromwell M (2015) Effect of individual Fc methionine oxidation on FcRn binding: Met252 oxidation impairs FcRn binding more profoundly than Met428 oxidation. J Pharm Sci 104:368-377

Ghetie V, Ward ES (1997) FcRn: the MHC class I-related receptor that is more than an IgG transporter. Immunol Today 18:592-598

Gibiansky L, Gibiansky E, Kakkar T, Ma P (2008) Approximations of the target-mediated drug disposition model and identifiability of model parameters. J Pharmacokinet Pharmacodyn 35:573-591

Gilliland LK, Walsh LA, Frewin MR, Wise MP, Tone M, Hale G, Kioussis D, Waldmann $H$ (1999) Elimination of the immunogenicity of therapeutic antibodies. J Immunol 162:3663-3671

Glatt DM, Beckford Vera DR, Parrott MC, Luft JC, Benhabbour SR, Mumper RJ (2016) The interplay of antigen affinity, internalization, and pharmacokinetics on CD44-positive tumor targeting of monoclonal antibodies. Mol Pharm 13:1894-1903

Goetze AM, Liu YD, Zhang Z, Shah B, Lee E, Bondarenko PV, Flynn GC (2011) High-mannose glycans on the Fc region of therapeutic IgG antibodies increase serum clearance in humans. Glycobiology 21:949-959
Grimm HP (2009) Gaining insights into the consequences of targetmediated drug disposition of monoclonal antibodies using quasisteady-state approximations. J Pharmacokinet Pharmacodyn 36:407-420

Harding FA, Stickler MM, Razo J, DuBridge RB (2010) The immunogenicity of humanized and fully human antibodies: residual immunogenicity resides in the CDR regions. MAbs 2:256-265

Hinton PR, Johlfs MG, Xiong JM, Hanestad K, Ong KC, Bullock C, Keller S, Tang MT, Tso JY, Vasquez M, Tsurushita N (2004) Engineered human IgG antibodies with longer serum half-lives in primates. J Biol Chem 279:6213-6216

Hinton PR, Xiong JM, Johlfs MG, Tang MT, Keller S, Tsurushita N (2006) An engineered human IgG1 antibody with longer serum half-life. J Immunol 176:346-356

Hotzel I, Theil FP, Bernstein LJ, Prabhu S, Deng R, Quintana L, Lutman J, Sibia R, Chan P, Bumbaca D, Fielder P, Carter PJ, Kelley RF (2012) A strategy for risk mitigation of antibodies with fast clearance. MAbs 4:753-760

Huang Q, Riviere JE (2014) The application of allometric scaling principles to predict pharmacokinetic parameters across species. Expert Opin Drug Metab Toxicol 10:1241-1253

Igawa T, Ishii S, Tachibana T, Maeda A, Higuchi Y, Shimaoka S, Moriyama C, Watanabe T, Takubo R, Doi Y, Wakabayashi T, Hayasaka A, Kadono S, Miyazaki T, Haraya K, Sekimori Y, Kojima T, Nabuchi Y, Aso Y, Kawabe Y, Hattori K (2010a) Antibody recycling by engineered $\mathrm{pH}$-dependent antigen binding improves the duration of antigen neutralization. Nat Biotechnol 28:1203-1207

Igawa T, Tsunoda H, Tachibana T, Maeda A, Mimoto F, Moriyama C, Nanami M, Sekimori Y, Nabuchi Y, Aso Y, Hattori K (2010b) Reduced elimination of $\lg$ antibodies by engineering the variable region. Protein Eng Des Sel 23:385-392

Igawa T, Maeda A, Haraya K, Tachibana T, Iwayanagi Y, Mimoto F, Higuchi Y, Ishii S, Tamba S, Hironiwa N, Nagano K, Wakabayashi T, Tsunoda H, Hattori K (2013) Engineered monoclonal antibody with novel antigen-sweeping activity in vivo. PLoS ONE 8:e63236

Igawa T, Haraya K, Hattori K (2016) Sweeping antibody as a novel therapeutic antibody modality capable of eliminating soluble antigens from circulation. Immunol Rev 270:132-151

Jackisch C, Muller V, Maintz C, Hell S, Ataseven B (2014) Subcutaneous administration of monoclonal antibodies in oncology. Geburtshilfe Frauenheilkd 74:343-349

James LC, Roversi P, Tawfik DS (2003) Antibody multispecificity mediated by conformational diversity. Science 299:1362-1367

Jefferis R (2009a) Glycosylation as a strategy to improve antibodybased therapeutics. Nat Rev Drug Discov 8:226-234

Jefferis R (2009b) Recombinant antibody therapeutics: the impact of glycosylation on mechanisms of action. Trends Pharmacol Sci 30:356-362

Jefferis R, Lund J (2002) Interaction sites on human IgG-Fc for FcgammaR: current models. Immunol Lett 82:57-65

Jones AJ, Papac DI, Chin EH, Keck R, Baughman SA, Lin YS, Kneer J, Battersby JE (2007) Selective clearance of glycoforms of a complex glycoprotein pharmaceutical caused by terminal $\mathrm{N}$ acetylglucosamine is similar in humans and cynomolgus monkeys. Glycobiology 17:529-540 
Junghans RP (1997) Finally! The Brambell receptor (FcRB). Mediator of transmission of immunity and protection from catabolism for IgG. Immunol Res 16:29-57

Kairemo KJ, Lappalainen AK, Kaapa E, Laitinen OM, Hyytinen T, Karonen SL, Gronblad M (2001) In vivo detection of intervertebral disk injury using a radiolabeled monoclonal antibody against keratan sulfate. J Nucl Med 42:476-482

Kanda Y, Yamada T, Mori K, Okazaki A, Inoue M, Kitajima-Miyama K, Kuni-Kamochi R, Nakano R, Yano K, Kakita S, Shitara K, Satoh M (2007) Comparison of biological activity among nonfucosylated therapeutic IgG1 antibodies with three different $\mathrm{N}$ linked Fc oligosaccharides: the high-mannose, hybrid, and complex types. Glycobiology 17:104-118

Keck R, Nayak N, Lerner L, Raju S, Ma S, Schreitmueller T, Chamow S, Moorhouse K, Kotts C, Jones A (2008) Characterization of a complex glycoprotein whose variable metabolic clearance in humans is dependent on terminal $\mathrm{N}$-acetylglucosamine content. Biologicals 36:49-60

Kelley M, Ahene AB, Gorovits B, Kamerud J, King LE, McIntosh T, Yang J (2013) Theoretical considerations and practical approaches to address the effect of anti-drug antibody (ADA) on quantification of biotherapeutics in circulation. AAPS $J$ 15:646-658

Kelly RL, Sun T, Jain T, Caffry I, Yu Y, Cao Y, Lynaugh H, Brown M, Vasquez M, Wittrup KD, Xu Y (2015) High throughput crossinteraction measures for human IgG1 antibodies correlate with clearance rates in mice. MAbs 7:770-777

Khawli LA, Goswami S, Hutchinson R, Kwong ZW, Yang J, Wang X, Yao Z, Sreedhara A, Cano T, Tesar D, Nijem I, Allison DE, Wong PY, Kao YH, Quan C, Joshi A, Harris RJ, Motchnik P (2010) Charge variants in $\operatorname{lgG} 1$ : isolation, characterization, in vitro binding properties and pharmacokinetics in rats. MAbs 2:613624

Kijanka G, Ipcho S, Baars S, Chen H, Hadley K, Beveridge A, Gould E, Murphy D (2009) Rapid characterization of binding specificity and cross-reactivity of antibodies using recombinant human protein arrays. J Immunol Methods 340:132-137

Kim JK, Tsen MF, Ghetie V, Ward ES (1994a) Catabolism of the murine $\lg \mathrm{G} 1$ molecule: evidence that both $\mathrm{CH}_{2}-\mathrm{CH}_{3}$ domain interfaces are required for persistence of $\lg \mathrm{G} 1$ in the circulation of mice. Scand J Immunol 40:457-465

Kim JK, Tsen MF, Ghetie V, Ward ES (1994b) Localization of the site of the murine $\lg 1$ molecule that is involved in binding to the murine intestinal Fc receptor. Eur J Immunol 24:2429-2434

Kobayashi H, Le N, Kim IS, Kim MK, Pie JE, Drumm D, Paik DS, Waldmann TA, Paik CH, Carrasquillo JA (1999) The pharmacokinetic characteristics of glycolated humanized anti-Tac Fabs are determined by their isoelectric points. Cancer Res 59:422430

Kohler G, Milstein C (1975) Continuous cultures of fused cells secreting antibody of predefined specificity. Nature 256:495-497

Lee HJ, Pardridge WM (2003) Monoclonal antibody radiopharmaceuticals: cationization, pegylation, radiometal chelation, pharmacokinetics, and tumor imaging. Bioconjug Chem 14:546-553

Li B, Tesar D, Boswell CA, Cahaya HS, Wong A, Zhang J, Meng YG, Eigenbrot C, Pantua H, Diao J, Kapadia SB, Deng R, Kelley RF (2014) Framework selection can influence pharmacokinetics of a humanized therapeutic antibody through differences in molecule charge. MAbs 6:1255-1264

Ling J, Zhou H, Jiao Q, Davis HM (2009) Interspecies scaling of therapeutic monoclonal antibodies: initial look. J Clin Pharmacol 49:1382-1402

Liu L (2015) Antibody glycosylation and its impact on the pharmacokinetics and pharmacodynamics of monoclonal antibodies and Fc-fusion proteins. J Pharm Sci 104:1866-1884

Liu L, Garcia AM, Santoro H, Zhang Y, McDonnell K, Dumont J, Bitonti A (2007) Amelioration of experimental autoimmune myasthenia gravis in rats by neonatal FcR blockade. J Immunol 178:5390-5398

Liu L, Stadheim A, Hamuro L, Pittman T, Wang W, Zha D, Hochman J, Prueksaritanont T (2011) Pharmacokinetics of IgG1 monoclonal antibodies produced in humanized Pichia pastoris with specific glycoforms: a comparative study with $\mathrm{CHO}$ produced materials. Biologicals 39:205-210

Liu L, Gomathinayagam S, Hamuro L, Prueksaritanont T, Wang W, Stadheim TA, Hamilton SR (2013) The impact of glycosylation on the pharmacokinetics of a TNFR2: Fc fusion protein expressed in glycoengineered Pichia pastoris. Pharm Res 30:803-812

Lobo ED, Hansen RJ, Balthasar JP (2004) Antibody pharmacokinetics and pharmacodynamics. J Pharm Sci 93:2645-2668

Lueking A, Beator J, Patz E, Mullner S, Mehes G, Amersdorfer P (2008) Determination and validation of off-target activities of antiCD44 variant 6 antibodies using protein biochips and tissue microarrays. Biotechniques $45: i-v$

Luu KT, Kraynov E, Kuang B, Vicini P, Zhong WZ (2013) Modeling, simulation, and translation framework for the preclinical development of monoclonal antibodies. AAPS J 15:551-558

Mager DE (2006) Target-mediated drug disposition and dynamics. Biochem Pharmacol 72:1-10

Mager DE, Jusko WJ (2001) General pharmacokinetic model for drugs exhibiting target-mediated drug disposition. J Pharmacokinet Pharmacodyn 28:507-532

Mao CP, Brovarney MR, Dabbagh K, Birnbock HF, Richter WF, Del Nagro CJ (2013) Subcutaneous versus intravenous administration of rituximab: pharmacokinetics, CD20 target coverage and B-cell depletion in cynomolgus monkeys. PLoS ONE 8: e80533

Mi Y, Lin A, Fiete D, Steirer L, Baenziger JU (2014) Modulation of mannose and asialoglycoprotein receptor expression determines glycoprotein hormone half-life at critical points in the reproductive cycle. J Biol Chem 289:12157-12167

Mould DR, Sweeney KR (2007) The pharmacokinetics and pharmacodynamics of monoclonal antibodies-mechanistic modeling applied to drug development. Curr Opin Drug Discov Dev 10:84-96

Mullamitha SA, Ton NC, Parker GJ, Jackson A, Julyan PJ, Roberts C, Buonaccorsi GA, Watson Y, Davies K, Cheung S, Hope L, Valle JW, Radford JA, Lawrance J, Saunders MP, Munteanu MC, Nakada MT, Nemeth JA, Davis HM, Jiao Q, Prabhakar U, Lang Z, Corringham RE, Beckman RA, Jayson GC (2007) Phase I evaluation of a fully human anti-alphav integrin monoclonal antibody (CNTO 95) in patients with advanced solid tumors. Clin Cancer Res 13:2128-2135

Muller PY, Milton M, Lloyd P, Sims J, Brennan FR (2009) The minimum anticipated biological effect level (MABEL) for selection 
of first human dose in clinical trials with monoclonal antibodies. Curr Opin Biotechnol 20:722-729

$\mathrm{Ng} \mathrm{CM}$, Stefanich E, Anand BS, Fielder PJ, Vaickus L (2006) Pharmacokinetics/pharmacodynamics of nondepleting anti-CD4 monoclonal antibody (TRX1) in healthy human volunteers. Pharm Res 23:95-103

Nisen M (2015) The best selling prescription drugs in the world last year. Quartz. Ref Type: Newspaper

Nose M, Wigzell H (1983) Biological significance of carbohydrate chains on monoclonal antibodies. Proc Natl Acad Sci USA 80:6632-6636

Notkins AL (2004) Polyreactivity of antibody molecules. Trends Immunol 25:174-179

Oitate M, Masubuchi N, Ito T, Yabe Y, Karibe T, Aoki T, Murayama N, Kurihara A, Okudaira N, Izumi T (2011) Prediction of human pharmacokinetics of therapeutic monoclonal antibodies from simple allometry of monkey data. Drug Metab Pharmacokinet 26:423-430

Olafsen T (2012) Fc engineering: serum half-life modulation through FcRn binding. Methods Mol Biol 907:537-556

Olafsen T, Kenanova VE, Wu AM (2006) Tunable pharmacokinetics: modifying the in vivo half-life of antibodies by directed mutagenesis of the Fc fragment. Nat Protoc 1:2048-2060

Onda M, Kreitman RJ, Vasmatzis G, Lee B, Pastan I (1999) Reduction of the nonspecific animal toxicity of anti-Tac(Fv)-PE38 by mutations in the framework regions of the Fv which lower the isoelectric point. J Immunol 163:6072-6077

Pan H, Chen K, Chu L, Kinderman F, Apostol I, Huang G (2009) Methionine oxidation in human lgG2 Fc decreases binding affinities to protein A and FcRn. Protein Sci 18:424-433

Patel DA, Puig-Canto A, Challa DK, Perez MH, Ober RJ, Ward ES (2011) Neonatal Fc receptor blockade by Fc engineering ameliorates arthritis in a murine model. J Immunol 187:10151022

Pennica D, Lam VT, Weber RF, Kohr WJ, Basa LJ, Spellman MW, Ashkenazi A, Shire SJ, Goeddel DV (1993) Biochemical characterization of the extracellular domain of the 75-kilodalton tumor necrosis factor receptor. Biochemistry 32:3131-3138

Richter WF, Jacobsen B (2014) Subcutaneous absorption of biotherapeutics: knowns and unknowns. Drug Metab Dispos 42:1881-1889

Richter WF, Gallati H, Schiller CD (1999) Animal pharmacokinetics of the tumor necrosis factor receptor-immunoglobulin fusion protein lenercept and their extrapolation to humans. Drug Metab Dispos 27:21-25

Richter WF, Bhansali SG, Morris ME (2012) Mechanistic determinants of biotherapeutics absorption following SC administration. AAPS J 14:559-570

Robbie GJ, Criste R, Dall'Acqua WF, Jensen K, Patel NK, Losonsky GA, Griffin MP (2013) A novel investigational Fc-modified humanized monoclonal antibody, motavizumab-YTE, has an extended half-life in healthy adults. Antimicrob Agents Chemother 57:6147-6153

Roche Media Release (2013) Herceptin SC formulation approval. Roche Media Release. Ref Type: Newspaper

Roche Media Release (2016) MABTHERA SC formulation EU approval. Roche Media Release. Ref Type: Newspaper
Roopenian DC, Akilesh S (2007) FcRn: the neonatal Fc receptor comes of age. Nat Rev Immunol 7:715-725

Rudnick SI, Lou J, Shaller CC, Tang Y, Klein-Szanto AJ, Weiner LM, Marks JD, Adams GP (2011) Influence of affinity and antigen internalization on the uptake and penetration of anti-HER2 antibodies in solid tumors. Cancer Res 71:2250-2259

Saber H, Gudi R, Manning M, Wearne E, Leighton JK (2016) An FDA oncology analysis of immune activating products and firstin-human dose selection. Regul Toxicol Pharmacol 81:448-456

Sachs UJ, Socher I, Braeunlich CG, Kroll H, Bein G, Santoso S (2006) A variable number of tandem repeats polymorphism influences the transcriptional activity of the neonatal Fc receptor alpha-chain promoter. Immunology 119:83-89

Salar A, Avivi I, Bittner B, Bouabdallah R, Brewster M, Catalani O, Follows G, Haynes A, Hourcade-Potelleret F, Janikova A, Larouche JF, Mclntyre C, Pedersen M, Pereira J, Sayyed P, Shpilberg O, Tumyan G (2014) Comparison of subcutaneous versus intravenous administration of rituximab as maintenance treatment for follicular lymphoma: results from a two-stage, phase IB study. J Clin Oncol 32:1782-1791

Sampei Z, Igawa T, Soeda T, Okuyama-Nishida Y, Moriyama C, Wakabayashi T, Tanaka E, Muto A, Kojima T, Kitazawa T, Yoshihashi K, Harada A, Funaki M, Haraya K, Tachibana T, Suzuki S, Esaki K, Nabuchi Y, Hattori K (2013) Identification and multidimensional optimization of an asymmetric bispecific IgG antibody mimicking the function of factor VIII cofactor activity. PLoS ONE 8:e57479

Schoch A, Kettenberger H, Mundigl O, Winter G, Engert J, Heinrich J, Emrich T (2015) Charge-mediated influence of the antibody variable domain on FcRn-dependent pharmacokinetics. Proc Natl Acad Sci USA 112:5997-6002

Shah DK, Betts AM (2013) Antibody biodistribution coefficients: inferring tissue concentrations of monoclonal antibodies based on the plasma concentrations in several preclinical species and human. MAbs 5:297-305

Shpilberg O, Jackisch C (2013) Subcutaneous administration of rituximab (MabThera) and trastuzumab (Herceptin) using hyaluronidase. Br J Cancer 109:1556-1561

Simister NE, Mostov KE (1989) An Fc receptor structurally related to MHC class I antigens. Nature 337:184-187

Somerfield J, Hill-Cawthorne GA, Lin A, Zandi MS, McCarthy C, Jones JL, Willcox M, Shaw D, Thompson SA, Compston AS, Hale G, Waldmann H, Coles AJ (2010) A novel strategy to reduce the immunogenicity of biological therapies. J Immunol 185:763768

Stefanich EG, Ren S, Danilenko DM, Lim A, Song A, lyer S, Fielder PJ (2008) Evidence for an asialoglycoprotein receptor on nonparenchymal cells for O-linked glycoproteins. J Pharmacol Exp Ther 327:308-315

Swiercz R, Chiguru S, Tahmasbi A, Ramezani SM, Hao G, Challa DK, Lewis MA, Kulkarni PV, Sun X, Ober RJ, Mason RP, Ward ES (2014) Use of Fc-engineered antibodies as clearing agents to increase contrast during PET. J Nucl Med 55:1204-1207

Tao MH, Morrison SL (1989) Studies of aglycosylated chimeric mouse-human IgG. Role of carbohydrate in the structure and effector functions mediated by the human IgG constant region. J Immunol 143:2595-2601 
Ternant D, Arnoult C, Pugniere M, Dhommee C, Drocourt D, Perouzel E, Passot C, Baroukh N, Mulleman D, Tiraby G, Watier H, Paintaud G, Gouilleux-Gruart V (2016) IgG1 allotypes influence the pharmacokinetics of therapeutic monoclonal antibodies through FcRn binding. J Immunol 196:607-613

Tsuchida D, Yamazaki K, Akashi S (2016) Comprehensive characterization of relationship between higher-order structure and FcRn binding affinity of stress-exposed monoclonal antibodies. Pharm Res 33:994-1002

UK Expert Scientific Group (2006) Expert Scientific Group on Phase I Clinical Trials. Ref Type: Pamphlet

Vaccaro C, Zhou J, Ober RJ, Ward ES (2005) Engineering the Fc region of immunoglobulin $\mathrm{G}$ to modulate in vivo antibody levels. Nat Biotechnol 23:1283-1288

van Meer PJ, Kooijman M, Brinks V, Gispen-de Wied CC, Silva-Lima B, Moors EH, Schellekens H (2013) Immunogenicity of mAbs in non-human primates during nonclinical safety assessment. MAbs 5:810-816

Vugmeyster Y, Szklut P, Wensel D, Ross J, Xu X, Awwad M, Gill D, Tchistiakov L, Warner G (2011) Complex pharmacokinetics of a humanized antibody against human amyloid beta peptide, antiabeta Ab2, in nonclinical species. Pharm Res 28:1696-1706

Wang W, Prueksaritanont T (2010) Prediction of human clearance of therapeutic proteins: simple allometric scaling method revisited. Biopharm Drug Dispos 31:253-263

Wang W, Wang EQ, Balthasar JP (2008) Monoclonal antibody pharmacokinetics and pharmacodynamics. Clin Pharmacol Ther 84:548-558

Wang DD, Zhang S, Zhao H, Men AY, Parivar K (2009) Fixed dosing versus body size-based dosing of monoclonal antibodies in adult clinical trials. J Clin Pharmacol 49:1012-1024

Wang W, Lu P, Fang Y, Hamuro L, Pittman T, Carr B, Hochman J, Prueksaritanont T (2011a) Monoclonal antibodies with identical Fc sequences can bind to FcRn differentially with pharmacokinetic consequences. Drug Metab Dispos 39:1469-1477

Wang W, Vlasak J, Li Y, Pristatsky P, Fang Y, Pittman T, Roman J, Wang Y, Prueksaritanont T, lonescu R (2011b) Impact of methionine oxidation in human IgG1 Fc on serum half-life of monoclonal antibodies. Mol Immunol 48:860-866

Wang W, Chen N, Shen X, Cunningham P, Fauty S, Michel K, Wang B, Hong X, Adreani C, Nunes CN, Johnson CV, Yin KC, Groff M, Zou Y, Liu L, Hamuro L, Prueksaritanont T (2012) Lymphatic transport and catabolism of therapeutic proteins after subcutaneous administration to rats and dogs. Drug Metab Dispos 40:952-962

Wang J, lyer S, Fielder PJ, Davis JD, Deng R (2016) Projecting human pharmacokinetics of monoclonal antibodies from nonclinical data: comparative evaluation of prediction approaches in early drug development. Biopharm Drug Dispos 37:51-65
Wittrup KD, Thurber GM, Schmidt MM, Rhoden JJ (2012) Practical theoretic guidance for the design of tumor-targeting agents. Methods Enzymol 503:255-268

Wright A, Morrison SL (1994) Effect of altered $\mathrm{CH}_{2}$-associated carbohydrate structure on the functional properties and in vivo fate of chimeric mouse-human immunoglobulin G1. J Exp Med 180:1087-1096

Wright A, Sato Y, Okada T, Chang K, Endo T, Morrison S (2000) In vivo trafficking and catabolism of IgG1 antibodies with $F c$ associated carbohydrates of differing structure. Glycobiology 10:1347-1355

Wu H, Pfarr DS, Johnson S, Brewah YA, Woods RM, Patel NK, White WI, Young JF, Kiener PA (2007) Development of motavizumab, an ultra-potent antibody for the prevention of respiratory syncytial virus infection in the upper and lower respiratory tract. J Mol Biol 368:652-665

Wynne C, Harvey V, Schwabe C, Waaka D, Mclntyre C, Bittner B (2013) Comparison of subcutaneous and intravenous administration of trastuzumab: a Phase $\mathrm{I} / \mathrm{lb}$ trial in healthy male volunteers and patients with HER2-positive breast cancer. J Clin Pharmacol. doi:10.1177/0091270012436560

Yeung YA, Leabman MK, Marvin JS, Qiu J, Adams CW, Lien S, Starovasnik MA, Lowman HB (2009) Engineering human IgG1 affinity to human neonatal Fc receptor: impact of affinity improvement on pharmacokinetics in primates. J Immunol 182:7663-7671

Yeung YA, Wu X, Reyes AE, Vernes JM, Lien S, Lowe J, Maia M, Forrest WF, Meng YG, Damico LA, Ferrara N, Lowman HB (2010) A therapeutic anti-VEGF antibody with increased potency independent of pharmacokinetic half-life. Cancer Res 70:3269-3277

Yu M, Brown D, Reed C, Chung S, Lutman J, Stefanich E, Wong A, Stephan JP, Bayer R (2012) Production, characterization, and pharmacokinetic properties of antibodies with $N$-linked mannose5 glycans. MAbs 4:475-487

Zahnd C, Kawe M, Stumpp MT, de Pasquale C, Tamaskovic R, Nagy-Davidescu G, Dreier B, Schibli R, Binz HK, Waibel R, Pluckthun A (2010) Efficient tumor targeting with high-affinity designed ankyrin repeat proteins: effects of affinity and molecular size. Cancer Res 70:1595-1605

Zheng Y, Tesar DB, Benincosa L, Birnbock H, Boswell CA, Bumbaca D, Cowan KJ, Danilenko DM, Daugherty AL, Fielder PJ, Grimm HP, Joshi A, Justies N, Kolaitis G, Lewin-Koh N, Li J, McVay S, O'Mahony J, Otteneder M, Pantze M, Putnam WS, Qiu ZJ, Ruppel J, Singer T, Stauch O, Theil FP, Visich J, Yang J, Ying Y, Khawli LA, Richter WF (2012) Minipig as a potential translatable model for monoclonal antibody pharmacokinetics after intravenous and subcutaneous administration. MAbs 4:243-255 